\title{
A continuous spectral aerosol-droplet microphysics model
}

\author{
Z. J. Lebo ${ }^{1}$ and J. H. Seinfeld ${ }^{1,2}$ \\ ${ }^{1}$ Environmental Science and Engineering, California Institute of Technology, Pasadena, 91125, CA, USA \\ ${ }^{2}$ Chemical Engineering, California Institute of Technology, Pasadena, 91125, CA, USA
}

Received: 28 July 2011 - Published in Atmos. Chem. Phys. Discuss.: 22 August 2011

Revised: 4 November 2011 - Accepted: 24 November 2011 - Published: 8 December 2011

\begin{abstract}
A two-dimensional (2-D) continuous spectral aerosol-droplet microphysics model is presented and implemented into the Weather Research and Forecasting (WRF) model for large-eddy simulations (LES) of warm clouds. Activation and regeneration of aerosols are treated explicitly in the calculation of condensation/evaporation. The model includes a 2-D spectrum that encompasses wet aerosol particles (i.e., haze droplets), cloud droplets, and drizzle droplets in a continuous and consistent manner and allows for the explicit tracking of aerosol size within cloud droplets due to collision-coalescence. The system of differential equations describing condensation/evaporation (i.e., mass conservation and energy conservation) is solved simultaneously within each grid cell. The model is demonstrated by simulating a marine stratocumulus deck for two different aerosol loadings (100 and $500 \mathrm{~cm}^{-3}$ ), and comparison with the more traditional microphysics modeling approaches (both 1-D bin and bulk schemes) is evaluated. The simulations suggest that in a 1-D bin microphysics scheme, without regeneration, too few particles are produced and hence the mode of the droplet size spectrum occurs at a larger size relative to the 2-D bin model results. Moreover, with regeneration, the 1-D scheme produces too many small droplets and thus shifts the mode toward smaller sizes. These large shifts in the droplet size distribution can potentially have significant effects on the efficiency of the collision-coalescence process, fall speeds, and ultimately precipitation.
\end{abstract}

\section{Introduction}

Numerical modeling of clouds presents a particularly challenging problem in that the underlying physical processes occur on the micro-scale, while the bulk quantities often ob-

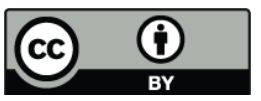

Correspondence to: Z. J. Lebo

(zachlebo@caltech.edu) served and predicted by models are on the macro-scale. In large-scale numerical models, e.g., regional climate models and general circulation models (GCM), cloud processes are prognostic but require significant assumptions about the details of the sub-gridscale processes (e.g., Sundqvist, 1988; Beheng, 1994; Del Genio et al., 1996; Rotstayn, 1997; Roeckner et al., 2003; Rotstayn and Liu, 2003a; Zhang et al., 2003; Morrison and Gettelman, 2008). As one moves toward models with smaller domains, e.g., numerical weather prediction models or cloud resolving models (CRM), relevant dynamical processes are better resolved and this requires more precise numerical cloud models. Frequently, single-moment or two-moment bulk microphysics schemes are employed in these models (e.g., Lin et al., 1983; Rutledge and Hobbs, 1983, 1984; Ferrier, 1994; Walko et al., 1995; Feingold et al., 1998; Rasch and Kristjansson, 1998; Simpson et al., 2003; Hong et al., 2004; Thompson et al., 2004; Morrison et al., 2005; Morrison and Pinto, 2005; Hong and Lim, 2006; Li et al., 2008; Thompson et al., 2008; Wang and Feingold, 2009a,b; Lim and Hong, 2010). These models predict either the first moment of a cloud particle size distribution (i.e., number concentration) or both the first and third moments (i.e., number concentration and mass mixing ratio), respectively. In general, the prognostic equations for changes both in number concentration and mass mixing ratio rely on an assumption regarding the shape of the size distribution of cloud particles. Here, "particles" refers to any of the following: cloud droplets, rain drops, pristine ice, snow (aggregates), graupel, and/or hail. By assuming a functional shape, e.g., a gamma distribution, changes in bulk cloud quantities can be analytically computed. However, such schemes lack the ability to accurately represent the various nonlinear processes within a cloud, i.e., collision-coalescence, aggregation, accretion, riming, etc., since the analytical solutions require gross assumptions regarding not only the size distribution shape, but also, fall speed, collection efficiency, etc.

In recent years, advances in computing efficiency and parallel processing have enabled the use of more detailed

Published by Copernicus Publications on behalf of the European Geosciences Union. 
cloud microphysics models, i.e., bin (or spectral) microphysics. These models have been developed for applications in both warm and mixed-phase clouds (e.g., Tzivion et al., 1987, 1989; Feingold et al., 1988; Reisin et al., 1996; Stevens et al., 1996; Geresdi, 1998; Geresdi and Rasmussen, 2005; Rasmussen et al., 1987; Khain et al., 2004; Khain and Pokrovsky, 2004; Khain and Lynn, 2009; Fan et al., 2009; Xue et al., 2010; Lebo and Seinfeld, 2011). Instead of tracking a single number concentration and mass for each type of cloud particle, the bin microphysics schemes discretize the distributions into size bins that span the smallest cloud droplets to large rain/graupel/snow/hail particles. The inherent nature of this approach allows for the explicit calculation of the collection processes within clouds based upon pair-wise collisions of cloud particles. Additionally, through size resolution, other processes, e.g., sedimentation, condensation/evaporation, deposition/sublimation, can be better simulated.

These approaches to simulating clouds, even in the most detailed case of the traditional bin microphysics scheme, still rely on assumptions, specifically regarding aerosol activation (i.e., the process by which a haze droplet or wet aerosol grows beyond its corresponding critical radius, $r_{\mathrm{c}}$, thus becoming a cloud droplet) and aerosol regeneration (this term refers to the mechanism by which an aerosol particle is formed as a cloud droplet evaporates). In reality, wet aerosols, cloud droplets, and drizzle droplets comprise a continuous spectrum defined by both the total size and the contained solute (aerosol) mass. Recently, Xue et al. (2010) demonstrated the significance of aerosol regeneration using a spectral bin microphysics model. Following Mitra et al. (1992), it is assumed that for each droplet that evaporates, one aerosol particle is generated from the solute contained in the droplet. However, the size of the regenerated aerosol is not known, since after the activated aerosol particle grows within the cloud droplet spectrum, information regarding the size of the activated aerosol is lost. Furthermore, the evaporation of cloud droplets is often simulated by predicting the amount of mass lost to the gas phase within a time step for a given droplet size, shifting the distribution, and rebinning the new cloud droplets into the Eulerian bins (Tzivion et al., 1989; Reisin et al., 1996; Khain et al., 2004; Lebo and Seinfeld, 2011). Thus, information regarding the size of the droplet before evaporation is lost after a single time step, making it difficult to use droplet size as a proxy for the regenerated aerosol size. In all, these assumptions regarding activation and regeneration represent a shortcoming in the current spectral bin microphysics models.

In previous works (e.g., Xue et al., 2010; Lebo and Seinfeld, 2011), the size distribution of the regenerated aerosols is prescribed to be lognormal (either with a single mode or bimodal). And since the actual size of the regenerated aerosols is not known, the shape of the regenerated lognormal distribution must also be predefined (often the shape parameters of the original distribution are used). This assumption introduces a bias in the modeled droplet number concentration that can be either positive or negative (i.e., leads to too many or too few cloud droplets), as will be explained shortly. In Fig. 1 a schematic of the relevant cloud microphysical process that control both the droplet size and solute mass are shown. Aerosol particles located in subsaturated regions will exist as haze particles. Upon activation, condensational growth increases the droplet mass while the solute mass remains constant. If the droplets are sufficiently large, collision-coalescence can become an important mechanism for not only cloud droplet growth, but also solute mass growth. Also, the solute mass in a droplet may have changed during the time in cloud due to collection, scavenging of aerosols, or in-situ chemical reaction. Thus, a shift in the size distribution toward larger sizes is expected, especially, in relatively clean environments where collision-coalescence is significant and efficient. Modeling the evolution of solute mass along with cloud droplet number concentration and mass is desirable.

The activation/regeneration problem can be summarized as follows (Fig. 1). An initial aerosol size $\left(D_{\mathrm{s}}\right)$ distribution $\left(N_{\mathrm{S}}\right)$ undergoes activation (left to right, red, solid); larger cloud condensation nuclei $(\mathrm{CCN})$ are more easily activated since a lower ambient supersaturation is required. These particles are then removed from the aerosol size distribution, leaving the non-activated particles. From this point, the manner in which the regeneration step is represented can affect the droplet (and aerosol) size distribution in two ways:

1. Negative Bias - In regions of entrainment, if all of the droplets within a grid box evaporate, the number concentration of regenerated aerosol particles $\left(N_{\text {reg }}\right)$ is identical to the original cloud droplet number concentration $\left(N_{\mathrm{d}}\right)$. A traditional approach is that these particles are described by the parameters used for the initial aerosol size distribution and are added to the existing distribution (black, dashed). However, during the activation process, the smaller aerosols do not activate and thus should not be regenerated. Here, we see that the aforementioned assumptions regarding aerosol regeneration begin to artificially enhance the aerosol number concentration in the smaller size bins (i.e., those particles that did not activate and likely will not activate). With subsequent evaporation/regeneration events this bias grows, and continuous activation and regeneration will lead to a significant, yet artificial, increase in small aerosol particles that are unlikely to activate since the available water vapor surplus is consumed by the larger aerosols and cloud droplets (thus reducing the supersaturation below that which would allow the smaller aerosol particles to activate). Consequently, fewer droplets are formed during activation and $N_{\mathrm{d}}$ is ultimately underpredicted, i.e., there is a negative bias in $N_{\mathrm{d}}$. 


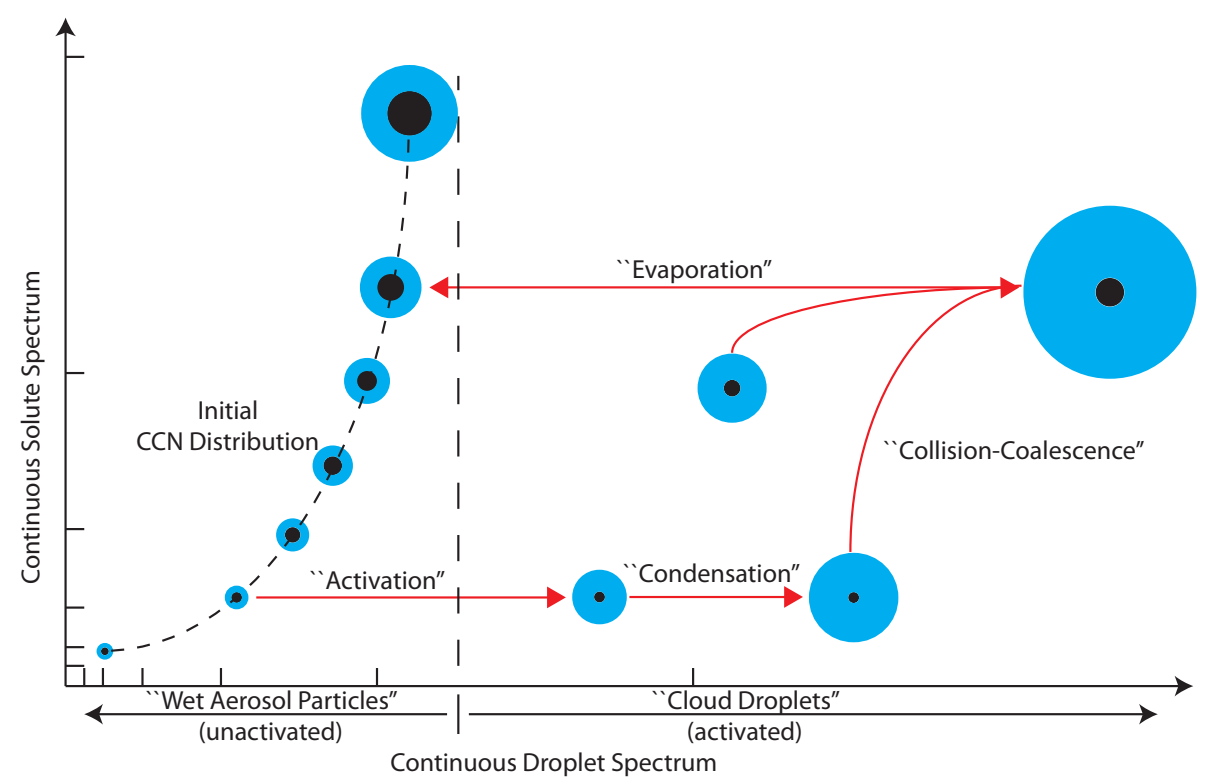

Fig. 1. Schematic of the microphysical process represented in the continuous 2-D spectral aerosol-droplet microphysics scheme.

2. Positive or Negative Bias - In the event that all of the droplets in a grid cell are not evaporated, large droplets will remain, while smaller droplets will completely evaporate (Pruppacher and Klett, 1997). The smaller, now evaporated droplets, were most likely formed on aerosol particles near to the cutoff size for activation (i.e., the critical supersaturation of these aerosols is just below the ambient supersaturation when activation occured) and should consequently return to the bins containing the smallest activated aerosols. Instead, these droplets are evaporated and the regenerated aerosol is spread over all sizes. This treatment produces excess small aerosols (similar to that shown above for the Negative Bias) but also produces excess larger aerosols. The larger aerosols are more likely to activate in a subsequent time step than their smaller counterparts (since the critical supersaturation for these particles is smaller). By spreading the distribution out over all sizes, particles will activate to form new cloud droplets in the presence of small supersaturations (even though, if the aerosols were placed in the correct location, the critical supersaturation ought to be too large for subsequent activation to occur). Here, a competition exists between the negative skewness caused by overproducing smaller aerosols and positive skewness caused generating excess larger aerosols. The former will suppress $N_{\mathrm{d}}$ while the latter will enhance $N_{\mathrm{d}}$.

An approach to reproducing or recycling aerosol particles was presented by Kogan et al. (1995) to attempt to account for the fact that smaller droplets (likely formed from smaller aerosol particles) will evaporate first and more readily. Here, the regenerated aerosols are assumed to go to the smallest size bin in the aerosol distribution until it attains its preactivated value (i.e., the number concentration that was set during the model initialization), then the second smallest bin is filled, and so on. This method, albeit more precise in that it will not artificially produce excess small particles, still lacks the ability to reproduce the ambient aerosol field after droplet evaporation, especially in conditions where the collision-coalescence process is a significant sink of small aerosols and a source of larger aerosols (as shown below).

Another method for simulating aerosol effects on clouds is to assume that the aerosol number concentration is fixed (e.g., Lu and Seinfeld, 2005, 2006; Sandu et al., 2008; Chen et al., 2011). Although this assumption circumvents the aerosol regeneration problem, fixing the aerosol number concentration may result in excess droplet formation. After activation, only those particles that are less likely to activate remain. On the next time step, if a supersaturation exists, as long as it is less than that of the previous time step, no new aerosols should activate (unless particles in the larger size categories are replenished by advection). But, in the case of fixed aerosol number concentration, the possibility exists for aerosol particles to activate and increase $N_{\mathrm{d}}$, leading to a positive bias in $N_{\mathrm{d}}$. Such a bias can lead to an artificial suppression of drizzle formation, increasing the LWP, or more vigorous evaporation in regions of entrainment since the droplets will be smaller (assuming the LWC is unchanged) acting to decrease the LWP. Obviously, these effects can offset one another, but in the case that they do not, the predicted LWP will likely not be correct.

To more accurately simulate the evolution of the continuous field that encompasses the spectrum from wet aerosols to drizzle droplets and address in detail the 
activation/regeneration problem in cloud models, we present here the implementation of a 2-D continuous spectral aerosol-droplet microphysics scheme coupled to a 3-D dynamical core for studying warm cloud microphysics. Recently, Ovchinnikov and Easter (2010) described a detailed 2-D fixed-bin (i.e., Eulerian) cloud microphysics scheme including chemistry, in which activated aerosols and interstitial wet aerosol particles are tracked within each grid point. The method does not include collision-coalescence and incorporates a linearized approximation to the droplet vapor growth equation. Collision-coalescence is an essential process for drizzle formation, and will alter the regenerated aerosol distribution, by shifting the solute mass to larger sizes.

The new method, as described in detail below, requires no a priori assumptions regarding aerosol activation and regeneration, since the treatment is explicitly accounted for via the representation of condensation/evaporation. Moreover, the solutions to the supersaturation (mass) and energy (temperature) equations are performed in a consistent, continuous, and simultaneous (i.e., latent heating and changes in the vapor surplus/deficit are computed with condensation/evaporation) manner including the effects of droplet curvature and solute mass on the condensation/evaporation rate of wet aerosol particles and cloud droplets. A detailed calculation of the collision-coalescence process is included to accurately represent both the evolution of the droplet spectrum due to pair-wise collisions, as well as the shift in the aerosol size distribution resulting from collision (either pair-wise collisions of cloud droplets or aerosol and cloud droplets, i.e., scavenging). Thus, the model includes the relevant physics in a manner that requires few assumptions unlike the more traditional 1-D bin microphysics schemes and bulk schemes. The continuous nature of the microphysics scheme allows one to address regeneration as well as determine the effect of cloud microphysics on the aerosol size distribution, an important component in determining the resulting aerosol spectrum after a cloud dissipates and accurately predicting evaporation rates in regions of entrainment.

The remainder of the work is organized as follows: Sect. 2 describes the 2-D continuous spectral aerosol-cloud microphysics model in detail as well as the alternative models used for comparative purposes. Section 3 discusses the dynamical model that is used as well as the model initialization. Numerical results are presented in Sect. 4, while Sect. 5 includes a discussion of the most important conclusions and future work.

\section{New 2-D spectral microphysics scheme}

The method developed here predicts the number of particles in a two-dimensional space, one dimension for the droplet size (mass or radius) and one for the solute size (mass or radius). One continuous 2-D size spectrum encompasses both aerosol particles and activated droplets and maintains the solute mass within activated droplets over the entire size spectrum. Even the most detailed bin microphysics schemes (e.g., Tzivion et al., 1987, 1989; Reisin et al., 1996; Stevens et al., 1996; Geresdi, 1998; Geresdi and Rasmussen, 2005; Rasmussen et al., 1987; Khain et al., 2004; Khain and Lynn, 2009; Xue et al., 2010) predict cloud particle sizes in just one dimension. Even with a detailed activation scheme that predicts droplet formation from a binned aerosol distribution (e.g., Xue et al., 2010), information regarding the size (and composition) of the aerosol particle after activation (i.e., from the dry aerosol distribution to the cloud droplet distribution) is not preserved. And, since the solute quantity in each droplet size bin is not computed and tracked, the regeneration of aerosol particles upon droplet evaporation must be parameterized. Although for each drop that evaporates, one aerosol particle is regenerated, aerosol scavenging by cloud/rain droplets, collision-coalescence, and aqueousphase chemistry alter the solute mass in each droplet, and thus affect the size distribution of regenerated aerosol. In this study we exclude aqueous-phase chemistry in order to focus on the overall effect of collision-coalescence on the solute mass distribution and consequently the regenerated aerosol distribution; however, aqueous-phase chemistry can, in principle, be included in the model. The 2-D method presented here requires no special assumptions and includes all important aerosol/cloud microphysical processes.

We assume mass doubling between droplet bins and aerosol bins, i.e.,

$x_{i+1}=2 x_{i}$

$x_{k+1}=2 x_{k}$,

respectively, where the subscripts $i$ and $k$ refer to the $i$-th bin of the droplet size dimension and the $k$-th bin of the aerosol size dimension. In other words, each particle lies in a bin $i$, $k$. For illustration, we assume that the smallest aerosol diameter is $0.05 \mu \mathrm{m}$ and the smallest droplet diameter is $0.05 \mu \mathrm{m}$ (sensitivity simulations show that the results are qualitatively similar for changes in the size of the smallest bins). We include 15 bins in the aerosol dimension and 36 bins in the droplet dimension such that the upper edge of the largest droplet size bin is $204.8 \mu \mathrm{m}$. Note that the smallest droplet size category corresponds to that of the smallest aerosol size bin. In the case that the ambient air is relatively dry, i.e., below the deliquescence point for the aerosol type, the particle will contain no water and thus its total size corresponds to just the aerosol size.

In any Eulerian bin microphysics scheme, the number of bins is always determined by the user. However, for specific cases, the number of bins should be extended toward larger sizes or can be reduced to only include smaller sizes. For example, to simulate Arctic stratus, Harrington et al. (2000) employed 25 bins while for simulations of deep convective clouds, Khain and Lynn (2009) and Lebo and Seinfeld (2011) used 33 and 36 bins, respectively, to capture large droplets 
and graupel. In determining the number of bins necessary for the study at hand, one must consider the differences in such things as terminal fall speed, activation, collection efficiency, etc., of the added or removed bins. In the case of the number of aerosol bins, we restricted the calculations to 15 bins. Simulations (not shown) with 20 bins were performed. There was no qualitative difference between the simulations using 15 and 20 bins. In fact this should be expected since the actual size of the aerosol upon regeneration and subsequent reactivation ought to only be important when the critical supersaturation of the newly formed particle is approximately that of the ambient supersaturation attained in the cloud during the simulation. Since the critical supersaturation of aerosol particles is not a linear function of size, adding bins with smaller sizes will act to increase the computational expense, with little to no change in the cloud properties since these particles are likely to not activate during the simulation. On the other hand, adding bins with larger sizes will also have little to no effect on the cloud properties since these particles have a very low critical supersaturation and thus will likely re-activate in the presence of any supersaturation. Thus, the chosen aerosol binning is dependent upon the ambient supersaturation within the cloud. For future studies of other cloud types, e.g., shallow convection, deep convection, etc., the aerosol size distribution will have to be extended to encompass particles with higher critical supersaturations since the ambient supersaturation in these cloud types is often higher than in the marine stratocumulus case chosen to demonstrate the model's implementation.

\subsection{Condensation/evaporation}

Condensation and evaporation are simulated by solving the set of ordinary differential equations that describe vapor deposition onto the particles, water mass conservation, energy conservation, and ambient supersaturation. The vapor deposition equation is defined as (Pruppacher and Klett, 1997):

$$
\frac{\mathrm{d} r_{i, k}}{\mathrm{~d} t}=\frac{G s}{r_{i, k}}\left[1-\frac{A}{r_{i, k}}+\frac{B_{k}}{r_{i, k}^{3}}\right]
$$

where,

$$
\begin{aligned}
& G=\left[\frac{R_{\mathrm{v}} T}{D_{\mathrm{v}}^{*} e_{\mathrm{s}}}+\frac{\Delta H_{\mathrm{v}}}{K_{\mathrm{T}}^{*} T}\left(\frac{\Delta H_{\mathrm{v}}}{R_{\mathrm{v}} T}-1\right)\right]^{-1} \\
& A=\frac{2 \sigma_{\mathrm{w}}}{\rho_{1} R_{\mathrm{v}} T} \\
& B_{k}=\frac{3 i m_{\mathrm{s}_{k}}}{4 \pi \rho_{1}} \frac{M_{\mathrm{w}}}{M_{\mathrm{s}}} .
\end{aligned}
$$

Here, $r_{i, k}$ is the radius of a droplet in bin $i, k, R_{\mathrm{V}}$ is the gas constant for water vapor, $D_{\mathrm{v}}^{*}$ is the diffusion coefficient of water vapor as a function of temperature $(T)$ and pressure $(P)$ including kinetic effects, $e_{\mathrm{S}}$ is the equilibrium vapor pressure over liquid water, $\Delta H_{\mathrm{v}}$ is the enthalpy of vaporization for water, $K_{\mathrm{T}}^{*}$ is the thermal conductivity of air as a function of $T$ including kinetic effects, $\sigma_{\mathrm{w}}$ is the surface tension of liquid water, $\rho_{\mathrm{l}}$ is the density of liquid water, $i$ is the ionic dissociation factor, $m_{\mathrm{s}_{k}}$ is the solute mass in aerosol bin $k, M_{\mathrm{W}}$ is the molar mass of water, and $M_{\mathrm{S}}$ is the molar mass of the solute (assumed to be ammonium sulfate for the cases presented herein). Following Pruppacher and Klett (1997), we express $D_{\mathrm{v}}^{*}$ and $K_{\mathrm{T}}^{*}$ as

$$
D_{\mathrm{v}}^{*}=\frac{D_{\mathrm{v}}}{\left[\frac{r_{i, k}}{r_{i, k}+\lambda_{\mathrm{v}}}+\frac{D_{\mathrm{v}}}{r_{i, k} \alpha_{\mathrm{c}}} \sqrt{\frac{2 \pi M_{\mathrm{w}}}{R T}}\right]}
$$

and

$$
K_{\mathrm{T}}^{*}=\frac{K_{\mathrm{T}}}{\left[\frac{r_{i, k}}{r_{i, k}+\lambda_{\mathrm{T}}}+\frac{K_{\mathrm{T}}}{r_{i, k} \alpha_{\mathrm{T}} \rho_{\mathrm{a}} c_{\mathrm{p}}} \sqrt{\frac{2 \pi M_{\mathrm{a}}}{R T}}\right]}
$$

where $D_{\mathrm{v}}$ is the unmodified diffusivity, $\lambda_{\mathrm{v}}$ is the vapor jump length (assumed to be equal to the mean free path of air molecules), $\alpha_{\mathrm{c}}$ is the condensation accommodation coefficient, $K_{\mathrm{T}}$ is the unmodified thermal conductivity of air, $\lambda_{\mathrm{T}}$ is the thermal jump distance, $\alpha_{\mathrm{T}}$ is the thermal accommodation coefficient, $c_{\mathrm{p}}$ is the heat capacity of air at constant pressure, $R$ is the universal gas constant and $M_{\mathrm{a}}$ is the molar mass of air. In the absence of ice, the mass conservation equation can be written simply as balance between the decrease (increase) of the vapor mixing ratio $\left(q_{\mathrm{v}}\right)$ due to condensation (evaporation) changing the liquid water mixing ratio $\left(q_{1}\right)$ :

$\frac{\mathrm{d} q_{\mathrm{v}}}{\mathrm{d} t}=-\frac{\mathrm{d} q_{1}}{\mathrm{~d} t}$

where

$\frac{\mathrm{d} q_{1}}{\mathrm{~d} t}=\frac{4 \pi \rho_{\mathrm{w}}}{\rho_{\mathrm{a}}} \sum_{i=1}^{N} \sum_{k=1}^{M} r_{i, k}^{2} \frac{\mathrm{d} r_{i, k}}{\mathrm{~d} t} N_{i, k}$

in which $\rho_{\mathrm{a}}$ is the ambient air density, $N$ and $M$ are the total number of bins in the droplet and aerosol dimensions, respectively, and $N_{i, k}$ is the number concentration of particles in bin $i, k$ in units of $\mathrm{kg}^{-1}$. Energy conservation is represented by

$$
\frac{\mathrm{d} T}{\mathrm{~d} t}=\frac{\Delta H_{\mathrm{v}}}{c_{\mathrm{p}}\left(1+q_{\mathrm{v}}\right)} \frac{\mathrm{d} q_{1}}{\mathrm{~d} t} .
$$

Here, the ambient temperature is modified due to latent heating induced by phase changes. Lastly, the supersaturation $(s)$ equation is represented by (Korolev and Isaac, 2003):

$$
\frac{\mathrm{d} s}{\mathrm{~d} t}=(s+1)\left[-\left(\frac{1}{q_{\mathrm{v}}}+\frac{\Delta H_{\mathrm{v}}^{2}}{c_{\mathrm{p}} R_{\mathrm{v}} T^{2}}\right) \frac{\mathrm{d} q_{1}}{\mathrm{~d} t}\right] .
$$

Equations (3), (9), (11), and (12) comprise a set of

$N_{\text {equ }}=\frac{M}{2}(M+1)+M(N-M)+3$

ordinary differential equations (where $N_{\text {equ }}$ is the number of equations). The solution to the set of equations is found by 
employing the Variable Order Differential Equation (VODE) solver of Brown et al. (1989). The solver is initialized with the ambient $q_{\mathrm{v}}, T, s$, and $N_{i, k}$ on each time step. The solver predicts the values of the given variables at the end of the time step and $q_{\mathrm{v}}, T$, and $s$ are updated accordingly. The droplets are rebinned into the Eulerian bins defined during the model initialization. This is done by assuming that the droplet distribution in each aerosol row of the 2-D mesh is piecewise linear. The new number concentration in each Eulerian bin is found by numerically integrating the piecewise linear distribution. It is important to note that during a time step, the condensation/evaporation algorithm conserves both water mass (i.e., the sum of the water vapor and droplet mixing ratios is fixed) and aerosol mass. The aerosol mass is conserved, since, as shown in Fig. 1, condensation/evaporation moves droplets left and right in the 2D space (up and down movements, or shifts in the aerosol size bin, is not permitted). This is justified since, physically, in the absence of aqueous phase chemistry, the soluble aerosol mass in a droplet will not change during condensation/evaporation.

\subsection{Sedimentation}

The terminal fall speeds required to compute sedimentation are calculated following Beard (1976) in which the particles are categorized into different regimes based upon their Reynolds number. The change in mass and number within a grid box due to sedimentation is computed then by predicting the mass and number that fall into the box from above and subtracting the mass and number that fall out of the box and into the box below. At the lowest level, the loss of mass through the bottom boundary is considered precipitation. This algorithm is analogous to that which is used in the 1-D bin and bulk models. Therefore, the only difference between the representation of sedimentation amongst the models is in the calculation of the terminal fall speeds (the bulk model has the least complex and fastest calculation while the new continuous spectral scheme is more accurate and computationally expensive).

\subsection{Collision-coalescence and aerosol scavenging}

The proposed 2-D microphysics scheme does not distinguish between collisions of cloud droplets and collisions of aerosol particles with cloud droplets since the entire particle spectrum is continuous (i.e., the aerosol is included in the droplet size). Moreover, due to the large difference in timescales between the collection process and vapor deposition, we separate the collection calculations from the vapor deposition. The former occurs over 10s of minutes (e.g., Tzivion et al., 1987; Bott, 1998) while the latter occurs over the course of a few seconds (e.g., Chuang et al., 1997; Pruppacher and Klett, 1997) Another reason for doing so is that the collection process does not affect the ambient water vapor mixing ratio (note that the equilibrium vapor pressure will change slightly since larger drops require less water vapor in the gas phase to maintain equilibrium), temperature, or supersaturation directly. The calculations are performed as follows.

For numerical implementation, we employ the flux method of Bott (1998). (Bott, 2000, proposed a method by which the 2-D collection problem can be reduced to a 1-D problem and then extrapolated back to 2-D. We find that it is best to apply the 1-D method of Bott, 1998, in two-dimensions to minimize the loss of information when the problem is simplified to a 1-D collection problem.) Collisions between every pair of bins are explicitly calculated. We follow the parabolic flux method proposed in Bott (1998) to limit upstream numerical diffusion.

We can express the loss of particles in bin $i, k$ due to collisions with particles in bin $j, l\left(\Delta N_{(i, k)-(j, l)}\right)$ as

$\left.\Delta N_{(i, k)-(j, l)}\right|_{\text {loss }}=N_{i, k} N_{j, l} K_{i, j} \Delta t$

where $N_{i, k}$ and $N_{j, l}$ are the number of particles in bins $i$, $k$ and $j, l$, respectively, $K_{i, j}$ is the collection kernel for the collisions between the $i$-th and $j$-th droplet bins (the solute is assumed to have a negligible impact on the kernels), and $\Delta t$ is the time step. Assuming the collection kernel is symmetric,

$\left.\Delta N_{(i, k)-(j, l)}\right|_{\text {loss }}=\left.\Delta N_{(j, l)-(i, k)}\right|_{\text {loss }}=\left.\Delta N_{(i, k)-(j, l)}^{(n, m)}\right|_{\text {gain }}$

in which $\left.\Delta N_{(i, k)-(j, l)}^{(n, m)}\right|_{\text {gain }}$ represents the gain of particles in bin $n, m$ due to collisions between droplets in bins $i, k$ and $j, l$. The subscripts $n$ and $m$ correspond to the droplet and aerosol bins, respectively, that contain the particles formed by collisions between particles in bins $i, k$ and $j, l$. Note that the well known problem occurs in which the newly formed droplets do not necessarily coincide with a 2-D bin size. Thus, following Bott (1998) the new particles are added to bin $n, m$ such that

$N_{n, m}^{\prime}=N_{n, m}+\left.\Delta N_{(i, k)-(j, l)}^{(n, m)}\right|_{\text {gain }}$

where the ' denotes an intermediary number concentration used to compute the flux to surrounding bins. Unlike the pure 1-D collection scenario, wherein a single flux through the upper boundary of the bin must be computed, the 2-D case requires 3 fluxes. Here, we can write the updated number concentrations in the bins affected by collisions between bins $i, k$ and $j, l$ as

$$
\begin{aligned}
& N_{n, m}=N_{n, m}^{\prime}-f_{n+1 / 2, m}-f_{n, m+1 / 2} \\
& N_{n+1, m}=N_{n+1, m}+f_{n+1 / 2, m}-f_{n+1, m+1 / 2} \\
& N_{n, m+1}=N_{n, m+1}+f_{n, m+1 / 2} \\
& N_{n+1, m+1}=N_{n+1, m+1}+f_{n+1, m+1 / 2}
\end{aligned}
$$

where $f$ denotes the flux through the boundary given by the subscript. For example, $f_{n+1 / 2, m}$ is the flux from bin $n, m$ to 
$n+1, m$. First, $f_{n+1 / 2, m}$ is computed and used to calculate the following

$N_{n, m}^{\prime \prime}=N_{n, m}^{\prime}-f_{n+1 / 2, m}$

$N_{n+1, m}^{\prime}=N_{n+1, m}+f_{n+1 / 2, m}$

where the added 's denote an intermediary number concentration. These values are then used to compute the flux through the $m+1 / 2$ boundary, i.e., $f_{n, m+1 / 2}$ and $f_{n+1, m+1 / 2}$. For the 2-D case, similar to Bott (1998) we can express $f_{n+1 / 2, m}$ as a polynomial expression of order 2

$f_{n+1 / 2, m}=w_{(i, k)-(j, l)}^{(1)} \sum_{s=0}^{2} \frac{a_{n, m, s}}{(s+1) 2^{s+1}}\left[1-\left(1-2 c_{n, m}\right)^{s+1}\right]$

in which

$$
\begin{aligned}
& w_{(i, k)-(j, l)}^{(1)}=\frac{N^{\prime}}{N_{n, m}^{\prime}} \\
& a_{n, m, 0}=-\frac{1}{24}\left[N_{n+1, m}-26 N_{n, m}^{\prime}+N_{n-1, m}\right] \\
& a_{n, m, 1}=\frac{1}{2}\left(N_{n+1, m}-N_{n-1, m}\right) \\
& a_{n, m, 2}=\frac{1}{2}\left[N_{n+1, m}-2 N_{n, m}^{\prime},+N_{n-1, m}\right] \\
& c_{n, m}=\frac{x^{\prime}-x_{n, m}}{x_{n+1, m}-x_{n, m}}
\end{aligned}
$$

where $N^{\prime}=\left.\Delta N_{(i, k)-(j, l)}^{(n, m)}\right|_{\text {gain }}, x^{\prime}$ is the mass of a droplet formed by collisions between bins $i, k$ and $j, l, w_{(i, k)-(j, l)}^{(1)}$ is a weighting function, and $c_{n, m}$ can be thought of as a Courant number. The coefficients $a_{n, m, s}$ are computed by fitting the mass distribution curve to a polynomial of order 2 following Bott (1998). Similar expressions can be derived for the remaining two fluxes to get:

$$
f_{n, m+1 / 2}=w_{(i, k)-(j, l)}^{(2)} \sum_{s=0}^{2} \frac{a_{n, m, s}^{\prime}}{(s+1) 2^{s+1}}\left[1-\left(1-2 c_{n, m}\right)^{s+1}\right]
$$

in which

$$
\begin{aligned}
& w_{(i, k)-(j, l)}^{(2)}=\frac{N^{\prime}-f_{n+1 / 2, m}}{N_{n, m}^{\prime \prime}} \\
& a_{n, m, 0}^{\prime}=-\frac{1}{24}\left[N_{n, m+1}-26 N_{n, m}^{\prime}+N_{n, m-1}\right] \\
& a_{n, m, 1}^{\prime}=\frac{1}{2}\left(N_{n, m+1}-N_{n, m-1}\right) \\
& a_{n, m, 2}^{\prime}=\frac{1}{2}\left[N_{n, m+1}-2 N_{n, m}^{\prime}+N_{n, m-1}\right]
\end{aligned}
$$

$c_{n, m}=\frac{y^{\prime}-y_{n, m}}{y_{n, m+1}-y_{n, m}}$

and

$$
\begin{aligned}
f_{n+1, m+1 / 2}= & w_{(i, k)-(j, l)}^{(3)} \sum_{s=0}^{2} \frac{a_{n+1, m, s}}{(s+1) 2^{s+1}} \\
& {\left[1-\left(1-2 c_{n+1, m}\right)^{s+1}\right] }
\end{aligned}
$$

where

$$
\begin{aligned}
& w_{(i, k)-(j, l)}^{(3)}=\frac{f_{n+1 / 2, m}}{N_{n+1, m}^{\prime}} \\
& a_{n+1, m, 0}=-\frac{1}{24}\left[N_{n+1, m+1}-26 N_{n+1, m}^{\prime}+N_{n+1, m-1}\right] \\
& a_{n+1, m, 1}=\frac{1}{2}\left(N_{n+1, m+1}-N_{n+1, m-1}\right) \\
& a_{n+1, m, 2}=\frac{1}{2}\left[N_{n+1, m+1}-2 N_{n+1, m}^{\prime}+N_{n+1, m-1}\right] \\
& c_{n+1, m}=\frac{y^{\prime}-y_{n+1, m}}{y_{n+1, m+1}-y_{n+1, m}} .
\end{aligned}
$$

Here, the weighting functions $\left(w_{(i, k)-(j, l)}^{(2)}\right.$ and $w_{(i, k)-(j, l)}^{(3)}$ for the fluxes through the $n, m+1 / 2$ and $n+1, m+1 / 2$ boundaries, respectively) represent the updated change in droplet number concentration in bin $n, m$ and $n+1, m$ according to the flux $f_{n+1 / 2, m}$. Furthermore, $y$ refers to the aerosol masses ( $y^{\prime}$ is the aerosol mass created by collisions between droplets in bins $i, k$ and $j, l$. A diagram showing these calculations, demonstrating the directions in which mass "flows" due to collection for the various fluxes shown above, is presented in Fig. 2.

Lastly, we note that collisions between droplets (or even large $\mathrm{CCN}$ ) and small aerosol particles (i.e., radius $<2 \mu \mathrm{m}$ ) are very rare due to gravitational settling alone. For particles in this size range, the collection is more likely to be a result of Brownian diffusion to the droplets and large $\mathrm{CCN}$ and/or temperature and density gradients, i.e., themophoresis and diffusiophoresis, respectively. However, the temperature and density gradients within the cloud are not significant enough for thermophoresis or diffusiophoresis to be a significant mechanism for the loss of small aerosols. Moreover, simulations performed with Brownian diffusion included in the 2-D continuous bin scheme (not shown) resulted in a negligible effect on the various cloud properties presented below. It is important to note that Brownian diffusion, thermophoresis, and diffusiophoresis are not included in most 1-D bin or bulk models. Including such processes in the spectral scheme would warrant their inclusion in the other schemes as well and require numerous parameterizations. 


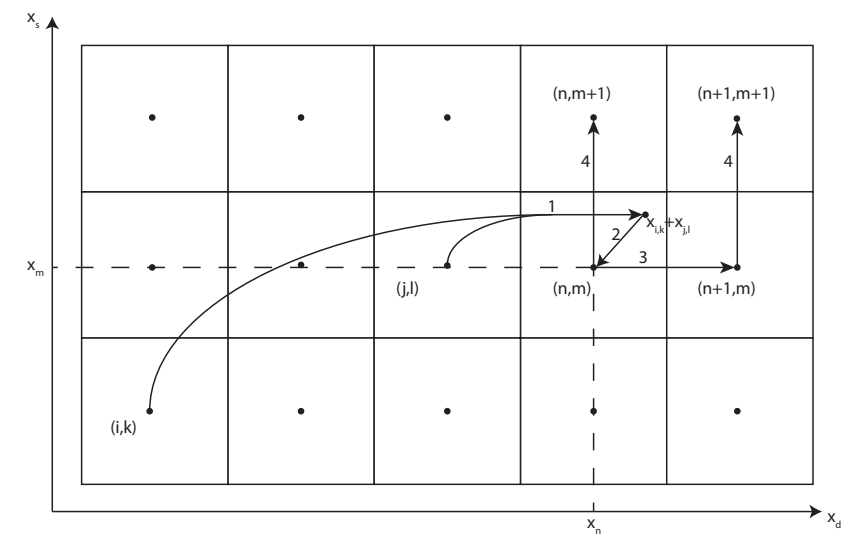

Fig. 2. Schematic of the 2-D collection problem for a mesh of particles with droplet mass $x_{\mathrm{d}}$ and solute mass $x_{\mathrm{s}}$. The calculations are performed in the following order: (1) droplets in bins $i, k$ and $j$, $l$ collide to form a droplet of mass $x_{i, k}+x_{j, l}$ in bin $n, m$. (2) The newly formed particles are added to $n, m$ to get $N_{n, m}^{\prime}$. (3) The flux through the $n+1 / 2, m$ boundary is computed and the particles are moved from bin $n, m$ to $n+1, m$ according to $f_{n+1 / 2, m}$. (4) The fluxes through the $n, m+1 / 2$ and $n+1, m+1 / 2$, i.e., $f_{n, m+1 / 2}$ and $f_{n+1, m+1 / 2}$, respectively, are then computed and the number concentrations in the surrounding 4 bins are updated accordingly.

\subsection{1-D bin microphysics model}

For comparative purposes, we will present results using the traditional 1-D bin microphysics approach. The particular form of the 1-D bin model is that described in Lebo and Seinfeld (2011), and the ice phase is excluded in the numerical calculations performed here. The 1-D bin model is configured for simulations in which aerosol particles are regenerated upon droplet evaporation as described in the Introduction (i.e., the regenerated aerosol size distribution is prescribed with the same shape parameters as the initial distribution).

\subsection{Bulk microphysics model}

A two-moment bulk microphysics model (Morrison et al., 2005; Morrison and Pinto, 2005) is employed in order to compare with the detailed 2-D microphysics scheme presented above. The bulk model is altered to include a detailed spectral representation of the aerosol size distribution following Lebo and Seinfeld (2011). As is the case of the 1-D bin scheme, simulations are performed in both the presence and absence of aerosol regeneration. In both the bulk model and the 1-D bin model, the regenerated aerosol size distribution is assumed to be lognormal with the same geometric mean diameter and standard deviation as the initial size distribution.

In addition to the modified version of the bulk microphysics scheme, we include for comparative purposes, a set of simulations performed with the bulk microphysics scheme without any modifications, i.e., no aerosol coupling (fixed

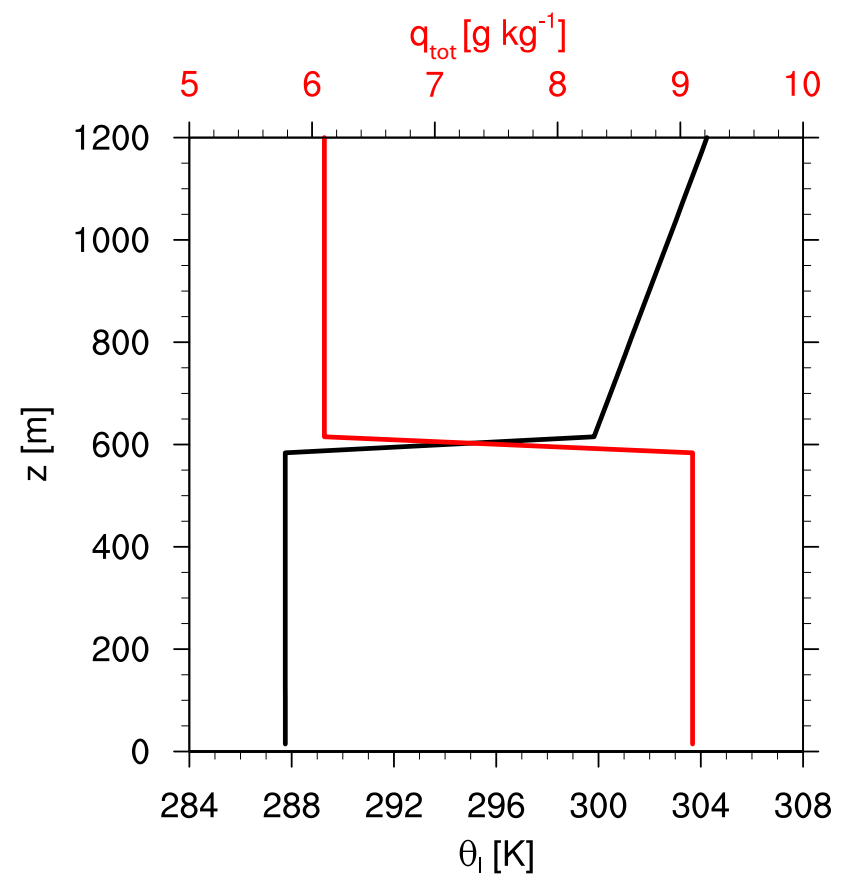

Fig. 3. Liquid potential temperature (black) and total water mixing ratio (red) used to initialize the model in the marine stratocumulus example.

droplet number concentration, $N_{\mathrm{d}}$ ). This microphysical option, obviously the fastest, lacks any link between aerosol particles and cloud droplets.

\section{Simulation of marine stratocumulus dynamics}

In order to compare the various microphysics models, we present simulations of a marine stratocumulus deck using an LES model. The stratified and closed nature of marine stratocumulus presents a good testbed for the 2-D continuous spectral warm-phase microphysics model. Also, marine stratocumulus is a well-studied cloud type via both insitu measurements and modeling studies (e.g., Stevens et al., 1998, 2003, 2005; Rotstayn and Liu, 2003b; Lu and Seinfeld, 2005, 2006; Bretherton et al., 2007; Sandu et al., 2008, 2009; Hill et al., 2008, 2009; Ackerman et al., 2009; Shao and Liu, 2009; Wang et al., 2009; Wang and Feingold, 2009b; Wang et al., 2010, 2011).

We employ the Weather Research and Forecasting (WRF) model, version 3.1.1 (Skamarock et al., 2008) for the dynamical core for the LES. All three microphysics schemes described in Sect. 2 are coupled to WRF. The model is initialized with the liquid water potential temperature $\left(\theta_{1}\right)$ and total water mixing ratio $\left(q_{\text {tot }}\right)$ shown in Fig. 3 based on the First International Satellite CLoud Climatology Project Regional Experiment (FIRE I) from Duynkerke et al. (2004) and as incorporated in Chen et al. (2011). Soundings from 
Table 1. Model configurations and microphysics descriptions.

\begin{tabular}{llllll}
\hline Designation & Type & Microphysics & Aerosol Activation & Aerosol Regeneration & Reference \\
\hline LES_2D & LES & 2-D Bin & Explicit & Explicit & Current study \\
LES_1D_Reg & LES & 1-D Bin & Parameterized & Parameterized & Lebo and Seinfeld (2011) \\
LES_1D_NoReg & LES & 1-D Bin & Parameterized & No & Lebo and Seinfeld (2011) \\
LES_Bulk_Reg & LES & 2-Moment Bulk & Parameterized & Parameterized & $\begin{array}{l}\text { Morrison et al. (2005) } \\
\text { Morrison and Pinto (2005) }\end{array}$ \\
& & & & & $\begin{array}{l}\text { Lebo and Seinfeld (2011) } \\
\text { andrison et al. (2005) } \\
\text { LES_Bulk_NoReg }\end{array}$ \\
& LES & 2-Moment Bulk & Parameterized & No & $\begin{array}{l}\text { Morrison and Pinto (2005) } \\
\text { Lebo and Seinfeld (2011) } \\
\text { Morrison et al. (2005) } \\
\text { LES_Bulk_NoAer* }\end{array}$ \\
& LES & 2-Moment Bulk & No & & Morrison and Pinto (2005) \\
\hline
\end{tabular}

* In this scenario, the bulk microphysics scheme of Morrison et al. (2005) and Morrison and Pinto (2005) is run without any modifications, i.e., no aerosol coupling (fixed droplet number concentration).

Table 2. LWP and relative change in comparison to the corresponding simulation performed with the 2-D bin microphysics scheme.

\begin{tabular}{lclllll}
\hline & \multicolumn{5}{c}{ LWP $\left[\mathrm{g} \mathrm{m}^{-2}\right]^{*}$} \\
\cline { 2 - 6 }$N_{\mathrm{CCN}}\left[\mathrm{cm}^{-3}\right]$ & LES_2D & LES_1D_Reg & LES_1D_NoReg & LES_Bulk_Reg & LES_Bulk_NoReg & LES_Bulk_NoAer \\
\hline 100 & 49.6 & $54.8(10.5 \%)$ & $52.3(5.4 \%)$ & $57.0(14.9 \%)$ & $29.7(-40.1 \%)$ & $55.5(11.9 \%)$ \\
500 & 54.5 & $48.3(-11.4 \%)$ & $53.0(-2.8 \%)$ & $59.9(9.9 \%)$ & $50.0(-8.3 \%)$ & $56.0(2.8 \%)$ \\
\hline
\end{tabular}

* The LWP is domain- and temporal-averaged for the final 30 min of the simulations. Relative changes are shown in parenthesis and are computed relative to the LES_2D simulations with the same $N_{\mathrm{CCN}}$.

FIRE I have been used in numerous modeling studies of marine stratocumulus (e.g., Hill et al., 2008, 2009; Chen et al., 2011). The sounding depicts a $600 \mathrm{~m}$ deep shallow boundary layer that is capped with a $12 \mathrm{~K}$ and $3 \mathrm{~g} \mathrm{~kg}^{-1}$ inversion in $\theta_{1}$ and $q_{\text {tot }}$, respectively. The zonal $(u)$ and meridional $(v)$ wind speeds are prescribed to be -1 and $6 \mathrm{~m} \mathrm{~s}^{-1}$, respectively, throughout the model domain. The LES model is initialized with a random $\pm 0.1 \mathrm{~K}$ temperature perturbation to initiate the eddies. For illustrative purposes, only nocturnal conditions are considered. The Rapid Radiative Transfer Model (RRTM) option in WRF is used for the longwave radiative transfer calculations. The monotonic advection scheme is used for the advection of all scalars. Surface latent heating and fluxes are computed following the Monin-Obukhov scheme.

Simulations are performed on a $1 \mathrm{~km} \times 1 \mathrm{~km} \times 1.6 \mathrm{~km}$ domain with a horizontal and vertical grid-spacing of 66.7 and $40 \mathrm{~m}$, respectively. The vertical resolution chosen for the current study is a bit lower than some of the recent detailed LES studies of marine stratocumulus (e.g., Hill et al., 2009; Chen et al., 2011), however, due to the increased complexity of the microphysics calculations required to explicitly represent the continuous 2-D aerosol-droplet spectrum, we relax the resolution somewhat in favor of a more detailed microphysics scheme. Since the purpose of this work is to illustrate the model's implementation in a 3-D LES model, the resolution should be appropriate to determine changes in the aerosol size distribution due to cloud processing. The model time step is $0.5 \mathrm{~s}$. Periodic boundary conditions are employed on both the zonal and meridional domain boundaries. The first $30 \mathrm{~min}$ are excluded from the analysis below due to model spin-up. Results are shown for the subsequent $2 \mathrm{~h}$.

To compare the different microphysics schemes defined in Sect. 2 with the 2-D continuous scheme, we perform simulations both with and without aerosol regeneration using the 1-D bin microphysics schemes, as well as a set of simulations with and without aerosol regeneration using the bulk scheme. Lastly, we perform simulations using the bulk microphysics model without aerosol coupling, i.e., fixed $N_{\mathrm{d}}$. For the purpose of the these simulations, we fix $N_{\mathrm{d}}$ at 100 and $400 \mathrm{~cm}^{-3}$ to represent the "Clean" and "Polluted" cases. These values are chosen so as to represent the number of droplets expected to activate in an environment with an aerosol number concentration of 100 and $500 \mathrm{~cm}^{-3}$, respectively. The suite of simulations is defined in Table 1, including details on the assumptions regarding activation and regeneration of aerosol particles. In those simulations with explicit aerosol activation, the model is initialized with a lognormal aerosol distribution:

$$
n^{\mathrm{d}}\left(D_{\mathrm{p}}\right) \equiv \frac{\mathrm{d} N}{\mathrm{~d} \ln D_{\mathrm{p}}}=\frac{N_{\mathrm{a}}}{\sqrt{2 \pi} \ln \sigma} \exp \left[-\frac{\ln ^{2}\left(\frac{D_{\mathrm{p}}}{D_{\mathrm{g}}}\right)}{2 \ln ^{2} \sigma}\right]
$$



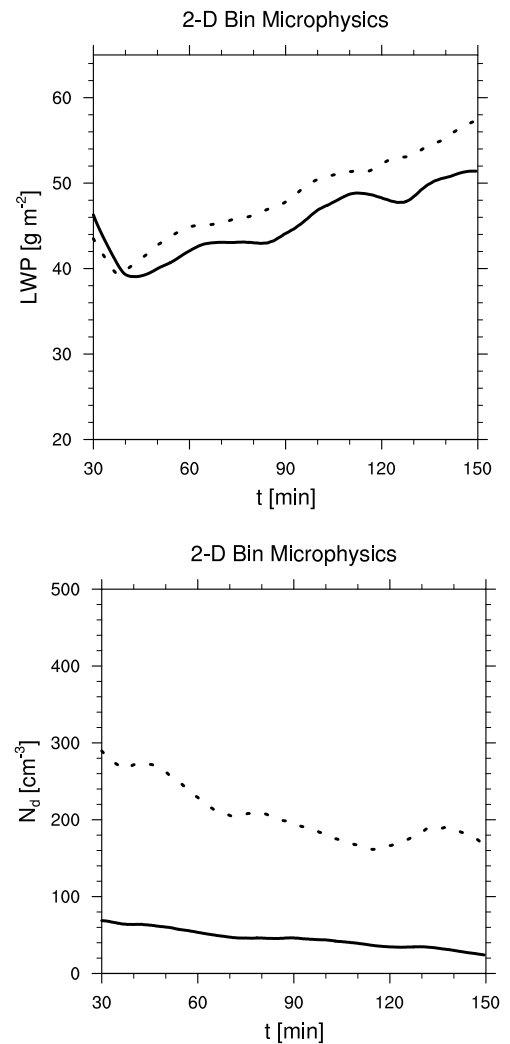

(a)
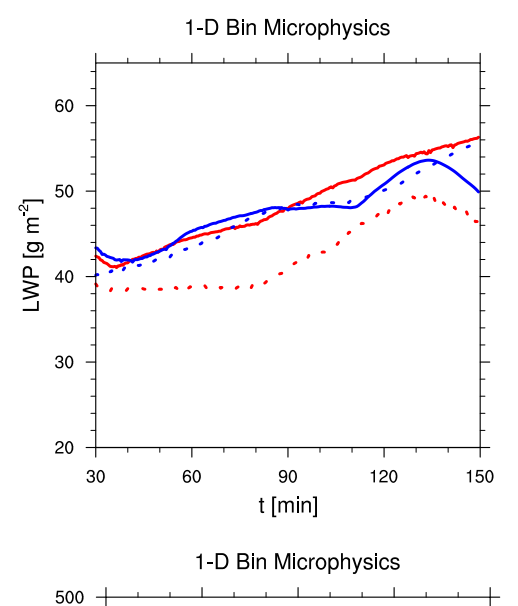

(b)

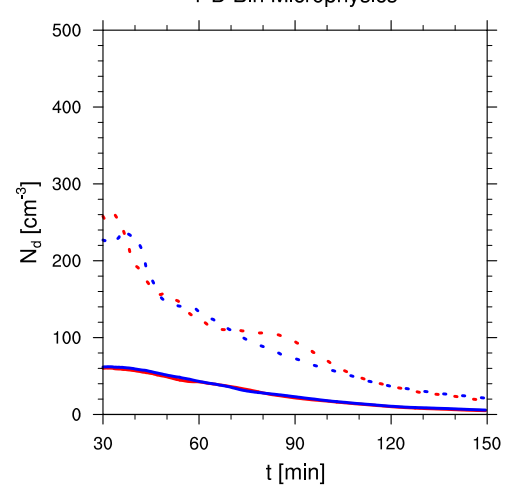

(d)

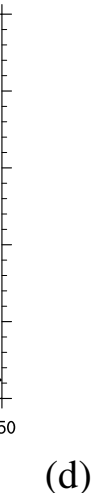

Fig. 4. Liquid water path (LWP) and droplet number concentration $\left(N_{\mathrm{d}}\right)$ for the set of simulations defined in Table 1 : LES_2D - (a) and (d) (black), LES_1D_Reg - (b) and (e) (red), LES_1D_NoReg - (b) and (e) (blue), LES_Bulk_Reg - (c) and (f) (green), LES_Bulk_NoReg - (c) and (f) (orange), and LES_Bulk_NoAer - (c) and (f) (cyan). Both the "Clean" (solid) and "Polluted" (dashed) cases are shown for all scenarios.

where, $N_{\mathrm{a}}$ is the total aerosol number concentration, $\sigma$ and $D_{\mathrm{g}}$ are the standard deviation and geometric mean diameter, respectively, and $D_{\mathrm{p}}$ is the aerosol particle diameter. For the purposes of illustration, we let $D_{\mathrm{g}}=0.1 \mu \mathrm{m}$ and $\sigma=1.8$.

In the 2-D continuous bin scheme, the initial aerosol distribution is binned in the 2-D space according to dry aerosol size and equilibrium wet size. The equilibrium size is computed by solving the equation for the equilibrium saturation ratio over a sphere of an aqueous solution (Pruppacher and Klett, 1997) using the bisection method. For grid points in which the saturation ratio $(S)$ is greater that 0.95 , we assume that the relative humidity (RH) is $95 \%$ for the purpose of initializing the model.

\section{Results}

\subsection{Comparison of microphysics schemes}

For comparison, we show the domain-averaged liquid water path (LWP) and conditionally-averaged droplet number concentration $\left(N_{\mathrm{d}}\right)$ in Fig. 4. Table 2 shows the LWPs at the end of the simulations and the changes relative to the LES_2D for the same $\mathrm{CCN}$ number concentration. For the most part, the models suggest a LWP of 46 to $62 \mathrm{~g} \mathrm{~m}^{-2}$ after $2.5 \mathrm{~h}$. The LES_Bulk_NoReg case with $N_{\mathrm{d}}=100 \mathrm{~cm}^{-3}$ is an outlier (orange, solid), predicting a LWP less than $30 \mathrm{~g} \mathrm{~m}^{-2}$ for most of the simulation. The reason for this disparity lies in the fact that if aerosols are not regenerated when a droplet evaporates (whether it be at cloud top due to entrainment or at cloud base due to sedimentation into subsaturated air), the evaporation serves as a sink for aerosol particles. Thus, instead of generating more aerosol particles that can activate and keep the droplet number concentration replenished, lack of regeneration leads to a gross underprediction of $N_{\mathrm{d}}$ (Hereinafter, it should be noted that all comparative statements refer to results relative to those from the 2-D continuous bin scheme, unless otherwise noted). In this case, the droplets will tend to be larger and thus the collision-coalescence process is artificially enhanced. The autoconversion parameterization (Khairoutdinov and Kogan, 2000) is solely a function of the bulk $N_{\mathrm{d}}$ and cloud liquid water content (LWC, $q_{\mathrm{c}}$ ). The autoconversion rate is proportional to $N_{\mathrm{d}}^{-1.79}$. Thus, a decrease in $N_{\mathrm{d}}$ results in a strong increase in the autoconversion rate, and enhanced drizzle formation. The drizzle drop 

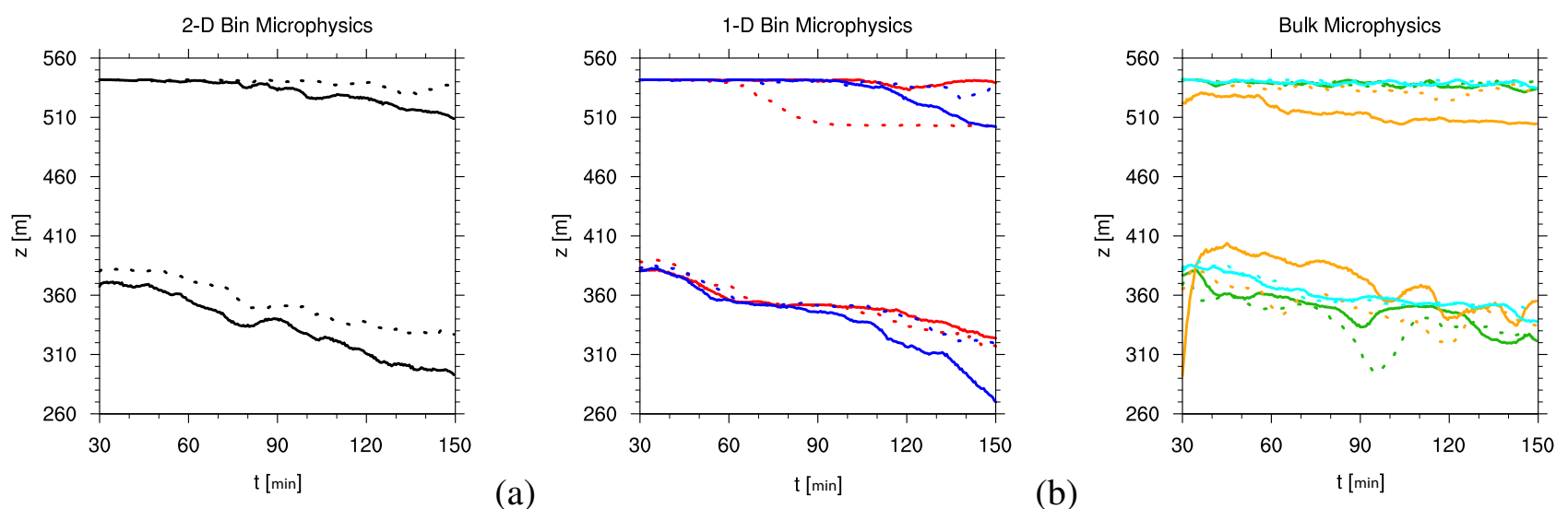

(c)

Fig. 5. Cloud top (top curves) and cloud base (bottom curves) for the suite of simulations described in Table 1, i.e., LES_2D - (a) (black), LES_1D_Reg - (b) (red), LES_1D_NoReg - (b) (blue), LES_Bulk_Reg - (c) (green), LES_Bulk_NoReg - (c) (orange), and LES_Bulk_NoAer - (c) (cyan). Both the "Clean" (solid) and "Polluted" (dashed) cases are shown for all scenarios.

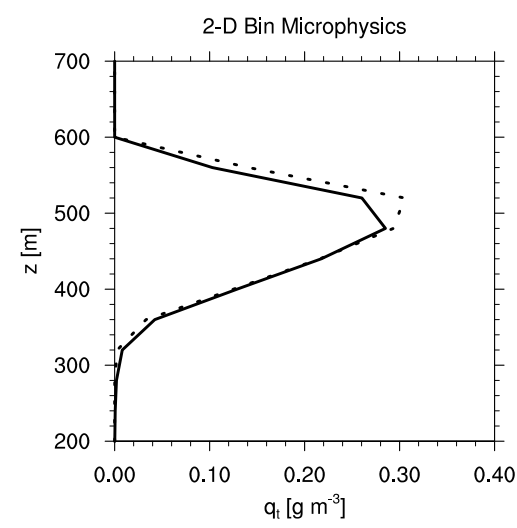

(a)

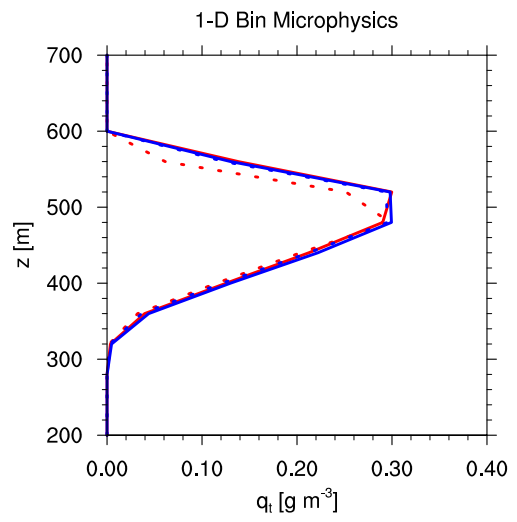

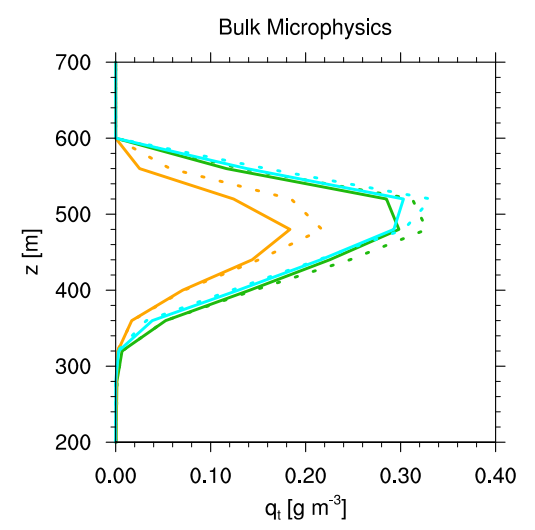

(c)

Fig. 6. Total condensed water $\left(q_{\mathrm{t}}\right)$. Colors are as in Fig. 5. Note that these are horizontally-averaged profiles of $q_{\mathrm{t}}$ at $2 \mathrm{~h}$ into the simulations.

formation occurs near cloud top, as expected since this region of the cloud contains the highest LWC. Ultimately, this leads to a decrease in the cloud top height (Fig. 5c) and a decrease in the LWC (due to smaller cloud depth and drizzle loss of condensed water). Interestingly, the LES_Bulk_NoAer performs much better since the assumption that $N_{\mathrm{d}}$ is fixed circumvents the aerosol problem in its entirety and acts to force $N_{\mathrm{d}}$ to stay relatively high (almost as if aerosols were being regenerated and activated again). However, the LWP is overpredicted in this case (Fig. 4 and Table 2).

Moreover, from Fig. 4f, we see the effect of the assumption of constant droplet number concentration. Comparison amongst the bin schemes suggests that this assumption overpredicts $N_{\mathrm{d}}$ by a factor of 2 in the "Clean" case and factor of 2 to 8 in the "Polluted" case. The addition of an explicit aerosol activation scheme produces LWPs that are in better agreement with the bin models. However, the bulk model is still not able to capture the change in $N_{\mathrm{d}}$ during the simulation (Fig. 4). These effects combine to produce an unrealistic profile of the domain-averaged total condensed water $\left(q_{\mathrm{t}}\right)$ profile for the LES_Bulk_NoReg cases (Fig. 6c). Here, we see evidence of the overpredicted autoconversion rate, suppressing the cloud top LWC and drizzle leading to a reduction in the mean LWC. Again, the simulations performed with an explicit binned-aerosol activation scheme better capture the vertical profile of $q_{\mathrm{t}}$, regardless of the regeneration assumption.

Figure $4 \mathrm{~d}, \mathrm{e}$, and $\mathrm{f}$ shows that in all but the LES_Bulk_NoAer case, there is a rapid decrease in $N_{\mathrm{d}}$. The decrease is largest in the simulations performed with bulk microphysics owing to its simplistic representation of the collision-coalescence process. One would expect that the decrease in $N_{\mathrm{d}}$ ought to be largest for the "Clean" cases since the particles ought to grow large enough such that the collision-coalescence process becomes quite efficient. However, Fig. 4d, e, and f suggests otherwise. Here however, it is difficult to distinguish between the loss of cloud droplets due to collection and the loss due to evaporation. In the "Clean" case, the in-cloud mean supersaturation ought to be higher and thus increasing the capability for smaller aerosols 


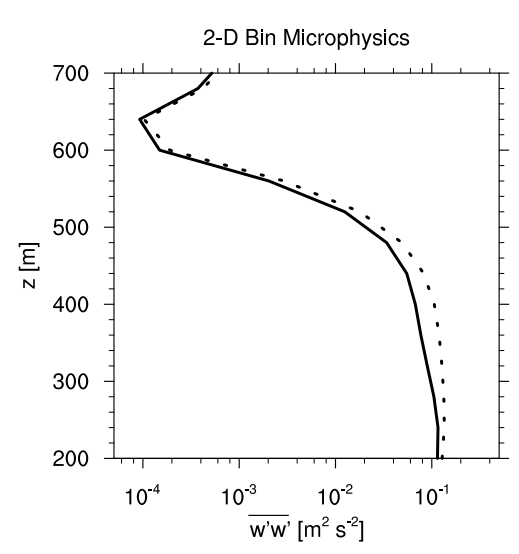

(a)

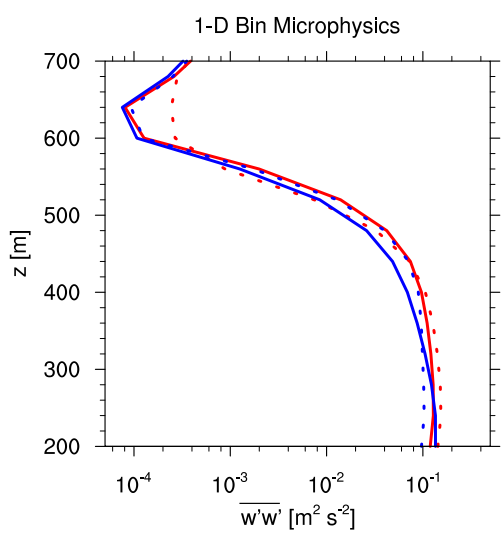

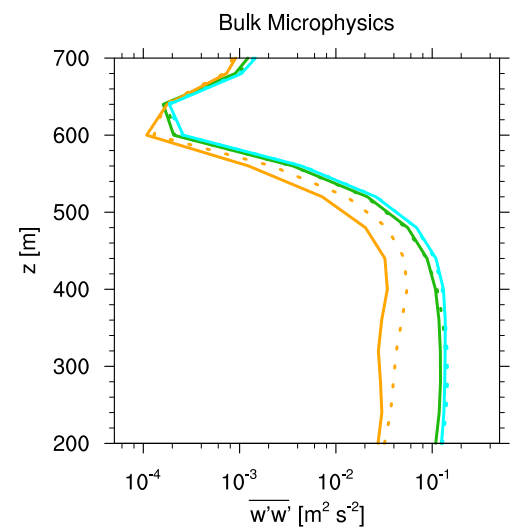

(b) (c)

Fig. 7. Vertical velocity variance $\left(\overline{w^{\prime} w^{\prime}}\right)$. The vertical profiles are averaged over the last $2 \mathrm{~h}$ of the simulations. Colors are as in Fig. 5 .

to remain activated. However, in the "Polluted" case, all aerosol particles initially activate within the cloud, but, as the larger, now more numerous, particles grow, the depletion in the water vapor mixing ratio causes the smaller droplets to evaporate. Hence, $N_{\mathrm{d}}$ decreases rapidly due to a combination of evaporation and collection. Moreover, the decrease in $N_{\mathrm{d}}$ is also partially related to the fact that as the cloud droplets are converted to rain droplets, the below-cloud layer becomes populated with small concentrations of sedimentating drops that ultimately reduce the average number concentration.

With the two bin microphysics schemes, we find that there is little agreement on the direction of the aerosol effect on the LWP. From Fig. 4a, the 2-D continuous bin model predicts that the LWP increases with increasing aerosol concentration (by $6 \mathrm{~g} \mathrm{~m}^{-2}$ at the end of the simulations). This is in agreement with previous modeling studies (e.g., Albrecht, 1989; Ackerman et al., 2003; Wood et al., 2009) and in-situ observations (Radke et al., 1989; Ferek et al., 2000). The increase in LWP results from changes near cloud top to an increase in aerosol loading. An increase in $\mathrm{CCN}$ number concentration lead to a monotonic increase in $N_{\mathrm{d}}$ and thus a less efficient collision-coalescence process. As a result, the droplets that reside near cloud top are smaller under polluted conditions and thus have a smaller terminal fall speed than analogous droplets in the "Clean" scenario. Consequently, the cloud top region moistens and stays elevated (Figs. 5a and 6a). A similar effect is seen in the simulations performed with the 1-D bin microphysics scheme without aerosol regeneration (Fig. 5b, blue). On the other hand, the simulations performed with the 1-D bin scheme including aerosol regeneration suggest that the LWP decreases with increased aerosol loading (Fig. 4, red and Fig. 5b). The reason for the switch in the sign of the effect on the LWP is due to an increase in entrainment at the cloud top-free troposphere interface. Figure 7 shows the horizontal- and temporal-averaged vertical velocity variance $\left(\overline{w^{\prime} w^{\prime}}\right)$, a proxy for the strength of turbulent mixing. For the LES_1D_Reg case (red, dashed), there is an in- crease in $\overline{w^{\prime} w^{\prime}}$ at the inversion level $(z=600 \mathrm{~m})$ relative to the "Clean" case (red, solid). This increase in mixing is caused by increased evaporation in the entrainment regions (regeneration produces more numerous, smaller aerosol particles that are more likely to evaporate), leading to an increase in entrainment and a positive feedback loop occurs with a further increase in evaporation near cloud top. Ultimately, this leads to a decrease in the LWP (the differences in modeled LWP are discussed in more detail below). This is corroborated by the decrease in $q_{\mathrm{t}}$ in Fig. $6 \mathrm{~b}$ and the decrease in LWP in Fig. 4. This effect is commonly referred to as the entrainment - evaporation effect for non-drizzling clouds (i.e., Wang et al., 2003; Xue and Feingold, 2006; Hill et al., 2008). On the other hand, the increase in LWP demonstrated by the 2-D continuous bin scheme for an increase in aerosol loading is suggestive of the cloud-lifetime effect (Albrecht, 1989), in which an increase in aerosol loading leads to more numerous, smaller droplets that mitigate the collision-coalescence process. Consequently, drizzle is suppressed and the LWP increases (Fig. 4a).

Owing to the inherent nature of the assumptions regarding aerosol regeneration and activation in the current 1-D bin schemes, the cloud droplet number concentration and LWP predicted could be biased (either positively or negatively) as discussed in the Introduction. In fact, the aerosol size distribution is constantly being modified by cloud processes (both microphysical and chemical, although the latter is not considered in the current study), thus the regenerated aerosol will not necessarily conform to the size distribution of the originally activated aerosol (see Sect. 1). The 2-D continuous bin microphysics scheme suggests that there is a negligible change in turbulent mixing at cloud top with an increase in aerosol loading (Fig. 7a) and thus increases in LWP (Fig. 4a), $q_{\mathrm{t}}$ near cloud top (Fig. 6a) and cloud top height (Fig. 5a) are observed.

Changes in aerosol loading near cloud base initiate a number of effects on marine stratocumulus dynamics. An 
increase in the $\mathrm{CCN}$ number concentration leads to smaller, more numerous droplets, slowing the collection process and suppressing drizzle. This leads to a decrease in both belowcloud evaporative cooling and latent heating within the cloud and consequently an increase in turbulent mixing near cloud base. More mixing implies more entrainment and an increase in evaporation that acts to decrease the LWP. This so-called drizzle-entrainment effect, counteracts the cloud lifetime effect mentioned above. Figure 7 demonstrates the increase in $\overline{w^{\prime} w^{\prime}}$ both within the cloud and at cloud base. Accordingly, as suggested by Lu and Seinfeld (2005) and Wood (2007), this leads to a decrease in $q_{\mathrm{t}}$ due to increased evaporation near cloud base. However, the decrease in $q_{\mathrm{t}}$ near cloud base due to increased aerosol loading is smaller than the opposing increase in $q_{\mathrm{t}}$ at cloud top. Thus, the overall effect is to increase the LWP of the cloud. Moreover, changes in cloud top may be mitigated by changes at cloud base (or even at cloud edges), thus a detailed model is necessary to simulate aerosol effects on cloud properties. The compensating effects of increased aerosol loading on cloud top and cloud base need not always favor increased LWC near cloud top (and thus an increase in LWP). The case presented here is representative of marine stratocumulus, but other factors can play a role in cloud dynamics near the boundaries, for example, sensitivity of marine stratocumulus to free tropospheric humidity (e.g., Ackerman et al., 2004), sea surface temperature (SST) (e.g., Lu and Seinfeld, 2005), diurnal heating (e.g., Hill et al., 2008; Sandu et al., 2009), entrainment rates (e.g., Wang et al., 2003; Xue and Feingold, 2006; Bretherton et al., 2007; Hill et al., 2009), and point sources, e.g., ships (e.g., Wang et al., 2011) under various aerosol loadings have been explored.

The reasons for the disparity in the sign of the effect on the LWP of increased aerosol loading between the 2-D continuous bin microphysics scheme and the 1-D bin scheme are three-fold. (1) The underlying assumptions involving regeneration of aerosol particles in the 1-D bin scheme erroneously produce particles that are either smaller or larger than their actual size after cloud microphysical processing. (2) The terminal fall speed $\left(v_{\mathrm{t}}\right)$ calculations are quite different. The 1-D bin model uses a simple (and efficient) size relation for $v_{\mathrm{t}}$ (i.e., $v_{\mathrm{t}}=A D_{\mathrm{d}}^{B}$, where $A$ and $B$ are empirical constants and $D_{\mathrm{d}}$ is the droplet size in a given bin in the 1-D model). Conversely, we have included the detailed calculation of $v_{\mathrm{t}}$ following Beard (1976) to more accurately represent the nonlinear nature of $v_{\mathrm{t}}$ as a function of droplet size. For intra-model consistency, the detailed calculations of $v_{\mathrm{t}}$ are also used to compute the collection kernels. And (3), the 1-D bin microphysics model does not include the effect of solute mass on condensation/evaporation. From Köhler Theory, we expect that a droplet containing a relatively large amount of solute will be less likely to evaporate since its critical supersaturation $\left(s_{\mathrm{c}}\right)$ is small (i.e., less than the ambient supersaturation within the cloud). Moreover, droplets formed on large $\mathrm{CCN}$ can be large enough to be considered a droplet (i.e., its diameter is more than $3 \mu \mathrm{m}$ ) even in a subsaturated environment.
In the absence of collision-coalescence, the slowed evaporation near cloud top due to increased solute mass ought to be rather insignificant since there are very few large aerosol particles present in the initial aerosol size distribution. However, as we show below, the collision-coalescence process is very efficient, especially in relatively clean environments, and consequently there is a significant increase in both the mean droplet size and solute mass. Since the highest LWC is found near cloud top, collection of cloud droplets is often most efficient in this region and thus one would expect to find that the increase in larger aerosol particles to be most substantial here. Hence, in the "Clean" scenario, the 1-D bin microphysics model does not agree with the the 2-D continuous bin scheme.

\subsection{Cloud microphysics effects on the aerosol size spectrum}

The 2-D continuous model allows for the analysis of microphysical effects on the aerosol size distribution. Larger aerosol particles are more readily activated, especially in regions of relatively high $\mathrm{CCN}$ number concentration, i.e., regimes in which the activation process (or formation of cloud droplets from haze particles) is vapor-limited and not $\mathrm{CCN}$-limited. In relatively clean environments, most, if not all, CCN activate to form cloud droplets. However, as the number concentration of $\mathrm{CCN}$ increases, the fraction of particles that ultimately activate decreases. In the transition region, from vapor-limited activation to $\mathrm{CCN}$-limited activation, the size distribution of the ambient aerosol becomes important. Moreover, the collision-coalescence process is still relatively efficient and consequently cloud microphysical processing ought to lead to the formation of larger aerosol particles, i.e., particles that are more readily activated after regeneration. The 2-D continuous microphysics scheme is designed to explicitly and physically represent the change in the aerosol size spectrum due to cloud microphysical processing.

As sketched in Fig. 1, cloud microphysical processing results in a shift in the aerosol size spectrum towards larger sizes; there is no cloud microphysics process by which aerosols become smaller. The increase in the mean size of the aerosol spectrum depends on the effectiveness of the collision-coalescence. The cloud radar reflectivity $(Z)$ defined as (Rogers and Yau, 1989)

$Z=10 \log \left[\sum_{i} \sum_{k} \int_{0}^{\infty} N_{i, k} D_{k}^{6} \mathrm{~d} D_{k}\right]$

where $D_{k}$ is the droplet diameter in the $k$-th droplet bin shows the effect of the microphysical processes (Fig. 8). Higher values of $Z$ (i.e., less negative) correspond to the production of larger cloud droplets and drizzle droplets. In the "Clean" case, $Z$ increases from its minimum of $-38 \mathrm{dBZ}$ at $35 \mathrm{~min}$ to $-19 \mathrm{dBZ}$ at the end of the simulation (an increase of $19 \mathrm{dBZ}$ ) while in the "Polluted" case, $Z$ increases from 


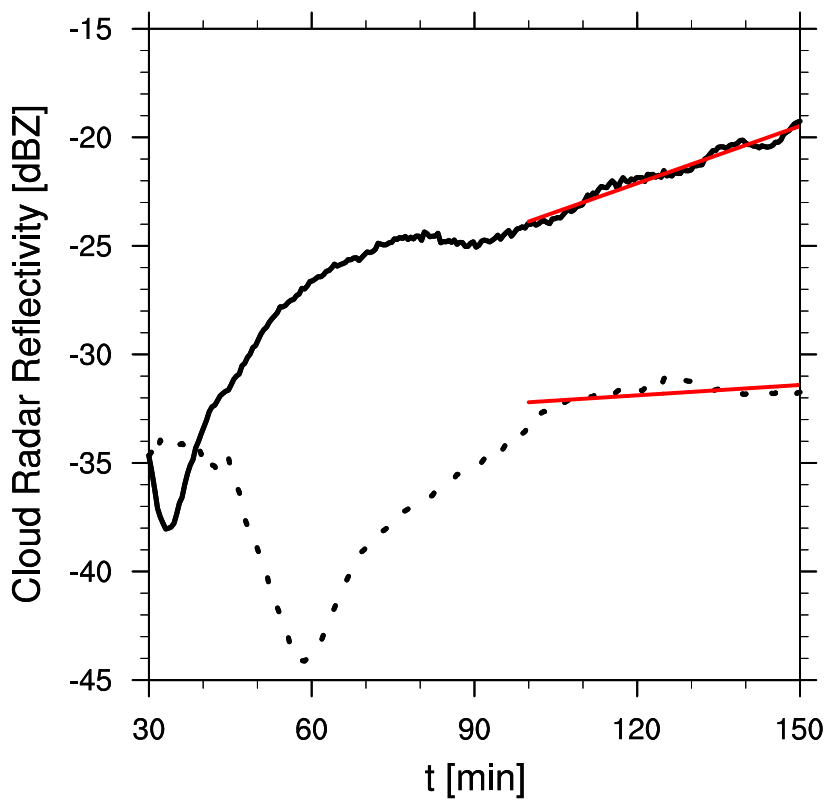

Fig. 8. Cloud radar reflectivity in $\mathrm{dBZ}$ for the simulations performed with the 2-D continuous bin microphysics scheme under "Clean" (solid) and "Polluted" (dashed) conditions. Reflectivities are averaged horizontally throughout the domain and vertically within the boundary layer.

$-44 \mathrm{dBZ}$ at $60 \mathrm{~min}$ to $-32 \mathrm{dBZ}$ at the end of the simulation (an increase of $12 \mathrm{dBZ}$ ). Linear regression lines are shown in Fig. 8 for the final 50 min of simulation time and the corresponding slopes $(m)$ are displayed to demonstrate the differences in collection efficiency between the "Clean" and "Polluted" cases; $Z$ increases at $10.6 \mathrm{dBZh}^{-1}$ during the final $50 \mathrm{~min}$ in the "Clean" case, while at only $1.9 \mathrm{dBZ} \mathrm{h}^{-1}$ in the "Polluted" case. Moreover, the increase in $Z$ from its minimum to its maximum in the "Clean" scenario is $58 \%$ larger than that of the "Polluted" scenario, clearly demonstrating the increase in efficiency of the collision-coalescence process in relatively clean conditions. Given the substantial increase in $Z$, even within a short period of time, it is expected that the change in the aerosol spectrum ought to be significant.

The enhancement in radar reflectivity is corroborated in Fig. 9 in which we show droplet distributions for the 2-D continuous bin model and the 1-D microphysics scheme with and without regeneration. Figure 9 clearly shows the reduction in the number concentration due to suppressed collision coalescence in the "Polluted" case compared with the "Clean" scenario. Furthermore, we see from the 1-D bin microphysics results, the effect of the regeneration assumption on the droplet size distribution. Specifically, at $150 \mathrm{~min}$, in the "Polluted" (dashed) scenario, Fig. 9 shows that the 1$\mathrm{D}$ bin model with regeneration produces many more smaller particles compared to the 2-D continuous bin scheme. The potential for the model to overpredict the number concentration was alluded to above and, demonstrated here, results in a large suppression in the formation of drizzle drops relative to the 2-D continuous scheme. Moreover, in the absence of a regeneration parameterization in the 1-D bin model, the mode of the droplet size spectrum is higher in comparison to the 2-D continuous bin scheme. This is a direct result of the fact that without a regeneration scheme, the droplet number concentration is likely to be underpredicted, hence producing larger droplets (assuming the liquid water content does not change much). Figure 9 alone demonstrates the large differences between the bin microphysical modeling approaches. These differences in the droplet size spectrum can potentially have a significant impact on the efficiency of the collision coalescence process as well as the terminal fall speeds (and ultimately precipitation).

In Fig. 10 we show the relative $\mathrm{CCN}$ number concentration at various times in the simulations $\left(R_{\mathrm{CCN}}\right)$. These calculations are done relative to the mean size distribution after the $30 \mathrm{~min}$ of spinup (this ensures that the results presented in Fig. 10 are not significantly affected by the initial thermal perturbation). Thus, $R_{\mathrm{CCN}}$ is defined as:

$R_{\mathrm{CCN}}(t)=\frac{N_{\mathrm{CCN}}(t)}{N_{\mathrm{CCN}}(t=30 \mathrm{~min})}$

where $N_{\mathrm{CCN}}(t)$ is the $\mathrm{CCN}$ (aerosol) number concentration at time $t$ and $N_{\mathrm{CCN}}(t=30 \mathrm{~min})$ is the $\mathrm{CCN}$ number concentration at $t=30 \mathrm{~min}$. If we first focus our attention on the "Clean" case in Fig. 10 (solid) and move from 45 min (black) to $150 \mathrm{~min}$ (red), we find that even after $2 \mathrm{~h}$, the collection process still significantly affects the aerosol size spectrum (as suggest by the monotonic increase in $Z$ from Fig. 8). In fact, after $150 \mathrm{~min}$ of simulation time (or, $2 \mathrm{~h}$ after the point at which the relative concentrations are defined), there is a substantial increase in particles in bins 10-14, reaching a maximum in bin 14 with $R_{\mathrm{CCN}}(t=150 \mathrm{~min})=9.2$. Thus, there is an increase, by nearly an order of magnitude, in the number of particles in this bin, solely as a result of the collisioncoalescence process. The collection of cloud droplets (either via collision-coalescence or aerosol scavenging) is the sole mechanism for this increase (i.e., we can rule out sedimentation and advection), since the calculations are horizontal averages within the boundary layer and Fig. 7a suggest that there is little mixing across the cloud top inversion (the source of fresh aerosol from above is negligible), and the cloud does not produce precipitation at the surface. This increase arises at the expense of smaller aerosol particles. At the end of the simulation, only about $40 \%$ of the particles in bins 1 through 6 remain relative to the number concentrations at $t=30 \mathrm{~min}$. (In traditional 1-D bin and bulk microphysics models with aerosol regeneration included, it is assumed that there is no change in the size distribution parameters of the regenerated aerosol.) Under relatively clean conditions, the arithmetic mean aerosol size increases from $0.119 \mu \mathrm{m}$ at $30 \mathrm{~min}$ to $0.138 \mu \mathrm{m} 2 \mathrm{~h}$ later. In other words, the mean size increases by $16 \%$ in $2 \mathrm{~h}$ for the "Clean" scenario. 


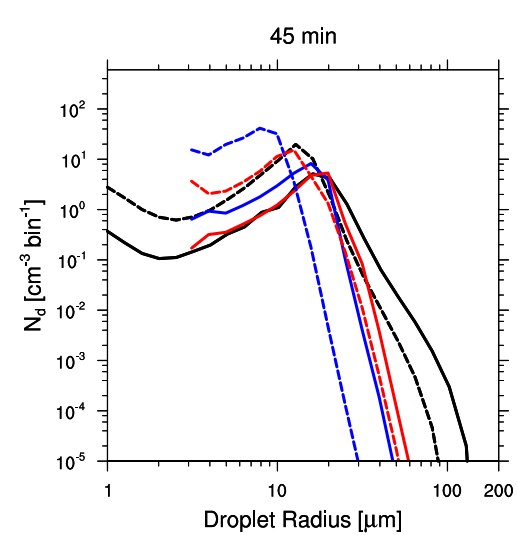

(a)

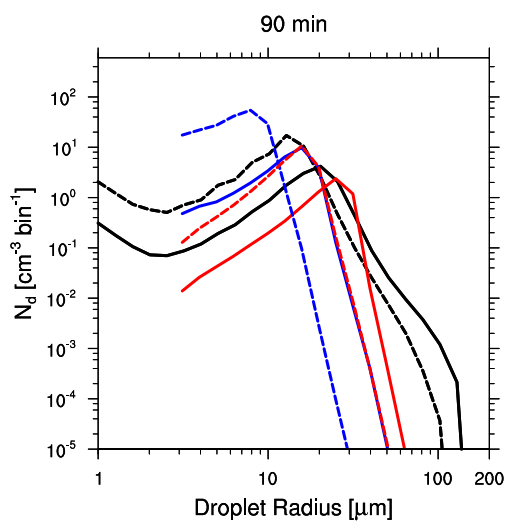

(b)

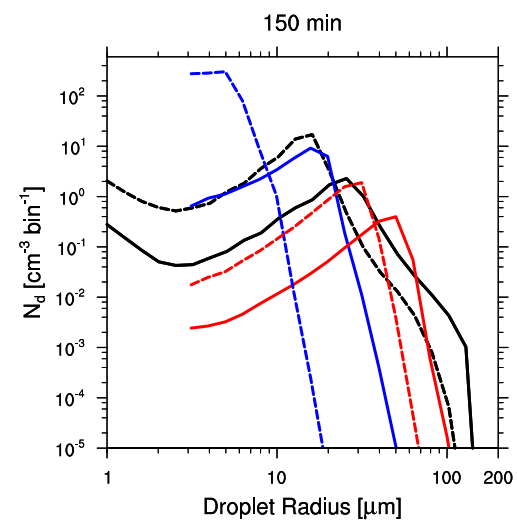

(c)

Fig. 9. Droplet size distributions at 45 (a), 90 (b), and 150 (c) min of simulation time. Spectra for simulations performed with the 2-D continuous bin scheme (black) as well as the 1-D bin microphysics model with regeneration (blue) and without regeneration (red) are shown for the "Clean" (solid) and "Polluted" (dashed) scenarios.

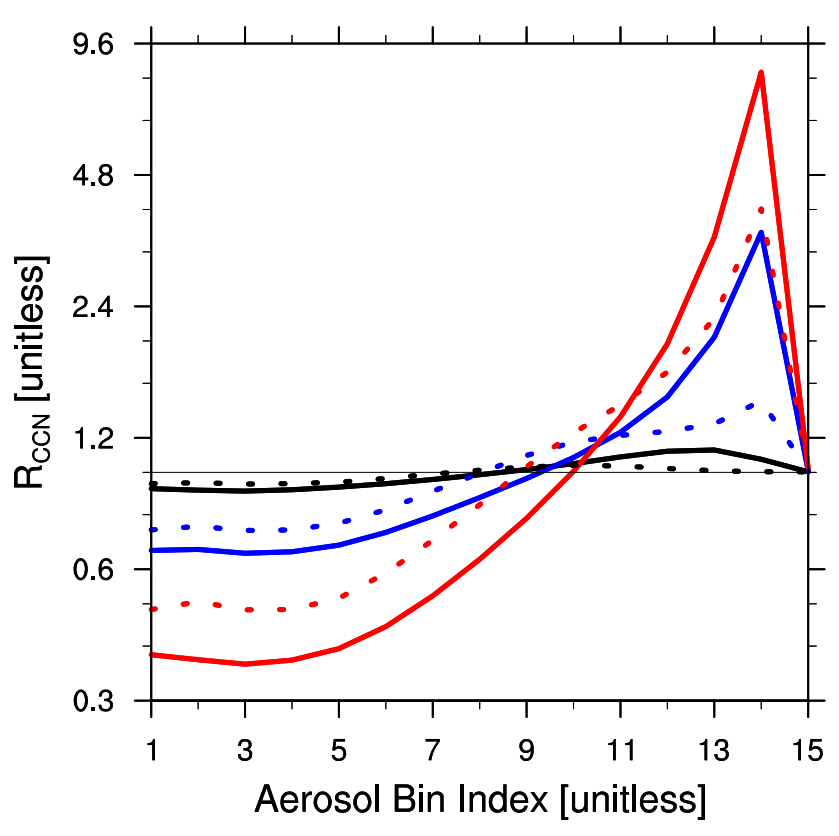

Fig. 10. Relative change in the $\mathrm{CCN}$ number concentration $\left(N_{\mathrm{CCN}}\right)$ after $45 \mathrm{~min}$ (black), $90 \mathrm{~min}$ (blue), $150 \mathrm{~min}$ (red). Both the "Clean" (solid) and "Polluted" (dashed) cases are shown. Note that the yaxis is a log-scale and that the area under the curves relative to the line $R_{\mathrm{CCN}}=1$ need not be 0 . In fact it should not be 0 since we use mass doubling between bins such that, for example, the diameter of particles in bin 8 are half that of particles in bin 11. Shown are the horizontally-averaged values within the boundary layer.

The increase in the $\mathrm{CCN}$ number concentration from the "Clean" to the "Polluted" case limits the production of larger cloud droplets and drizzle drops (Fig. 8) and consequently limits the conversion of aerosol particles to larger $\mathrm{CCN}$. From Fig. 10a (dashed), we find that there is a rather small change in the number concentrations in the larger bins until about $90 \mathrm{~min}$ into the simulations $(60 \mathrm{~min}$ after the chosen time to compute $R_{\mathrm{CCN}}$ ) since the collision-coalescence process is far less efficient in a polluted environment. However, at the end of the simulation, we find that the number concentration in bin 14 increases by a factor of 4 (albeit, less than half that shown for the "Clean" case above). Moreover, the number concentration of aerosol particles in bins 1 through 5 is about half that of the number present at $30 \mathrm{~min}$ into the simulation due to collection (collision-coalescence and/or aerosol scavenging). In other words, after $2 \mathrm{~h}$ of cloud microphysical processing the number of small aerosol particles is reduced by one-half. In this case, the mean aerosol size increases from $0.1175 \mu \mathrm{m}$ at $30 \mathrm{~min}$ to $0.133 \mu \mathrm{m} 2 \mathrm{~h}$ later, an increase of about $10 \%$ (roughly two-thirds of the increase in the mean aerosol size shown for the "Clean" case above). These changes in the aerosol size distribution are significant and suggest that the assumptions used regarding aerosol regeneration in traditional 1-D bin microphysics models (and even detailed bulk microphysics scheme) can lead to inaccuracies in the predicted LWP, distribution of LWC within the cloud, and an underestimation of $N_{\mathrm{d}}$.

The changes in the $\mathrm{CCN}$ number concentration presented here are obviously a factor of the meteorological conditions imposed. However, the collision-coalescence rate is controlled dominantly by $N_{\mathrm{d}}$ and $q_{\mathrm{t}}$ and consequently the change in aerosol distribution is also mostly affected by changes in $N_{\mathrm{d}}$ and $q_{\mathrm{t}}$. For clouds within the marine boundary layer, $q_{\mathrm{t}}$ is not significantly altered for an increase in the aerosol loading from 100 to $500 \mathrm{~cm}^{-3}$. However, the droplet number concentration is significantly larger. Thus, the droplet number concentration, which is inherently linked to the ambient CCN number concentration, should be the most significant factor in determining the collision-coalescence rate and consequently the change in the aerosol distribution due to cloud processing. Moreover, one can expect that for a thinner cloud (i.e., less than $250 \mathrm{~m}$ deep), $q_{\mathrm{t}}$ will be reduced, 
leading to a decrease in the size of the cloud droplets and less collision-coalescence. This will result in a smaller effect on the aerosol size distribution shift toward larger sizes. On the other hand, in a thicker cloud, (i.e., more than $300 \mathrm{~m}$ deep), $q_{\mathrm{t}}$ will be elevated, increasing the size of the cloud droplets, increasing the collision-coalescence rate, and potentially further enhancing the production of larger aerosol particles.

\section{Conclusions}

A 2-D continuous spectral aerosol-droplet microphysics model is presented and compared to the traditional microphysics approaches (i.e., 1-D bin models and bulk models). Unlike the now standard 1-D bin microphysics schemes, the aerosol size spectrum and the droplet size spectrum are joined together to create a 2-D continuous distribution encompassing both wet aerosol particles (i.e., haze particles), cloud droplets, and drizzle droplets. This approach requires no a priori assumptions regarding the activated size of nucleated droplets and the size of regenerated aerosol particles (i.e., those aerosol particles that are formed upon the evaporation of cloud droplets). The former is normally calculated by computing the nucleated droplet equilibrium size for small aerosol particles or by multiplying the aerosol size by a factor between 3 and 8 for larger aerosol particles (Kogan, 1991; Khain et al., 2000; Xue et al., 2010; Lebo and Seinfeld, 2011). Upon activation, an aerosol particle is lost. The regeneration process presents an additional complication and shortcoming in the traditional 1-D microphysics approach. While it is often assumed that each evaporated droplet forms one aerosol particle, the size of the newly formed aerosol particle is unknown and must be assumed. Yin et al. (2005), Wang et al. (2010), and Xue et al. (2010) demonstrate the significance of including aerosol regeneration in detailed cloud models, however the actual size of the regenerated particles is not known. The 2-D continuous bin microphysics scheme can be extended to include aqueous-phase chemistry and generate parameterizations for regenerated aerosol sizes.

We show that the collection process is a significant source of large aerosol particles, especially in relatively clean environments where the collision-coalescence process is rather efficient (an increase in large aerosols by nearly a factor of 10 after $2 \mathrm{~h}$ of cloud processing is shown). In the absence of aqueous-phase chemistry and collision-coalescence, the aerosol size spectrum is stagnant (assuming that the cloud is not precipitating to the surface). However, the collisioncoalescence process is a sink for cloud droplets and a source for larger cloud droplets and drizzle drops (and consequently is a sink of small aerosol particles and a source of larger aerosol particles). Without tracking the solute mass in a continuous aerosol-droplet spectrum, the regenerated aerosol distribution will have a bias and the evaporating of cloud droplets and subsequent activation of the regenerated aerosol will be erroneous. We demonstrate that the sign of the change in LWP due to an increase in aerosol loading is positive using the 2-D continuous bin model while it is negative using the 1-D bin model with regeneration. The 1-D model is not capable of accurately predicting the retarded evaporation of droplets containing larger solute mass (that resulted from collection within the cloud) and thus overpredicts the evaporation-entrainment effect near cloud top (e.g., Wang et al., 2003; Xue and Feingold, 2006; Hill et al., 2008).

The 2-D continuous spectral aerosol-droplet microphysics model is designed to simultaneously account for the depletion (production) of water vapor and heating (cooling) during condensation (evaporation). Traditionally (e.g., Tzivion et al., 1989; Reisin et al., 1996; Harrington et al., 2000; Khain and Lynn, 2009; Xue et al., 2010), the supersaturation change over the course of a time step is approximated and used to compute the condensation or evaporation of cloud droplets. The total change in mass is then used to compute the amount of latent heat release, and subsequently the ambient temperature is updated. However, in reality, the process is not step-wise but instead continuous, and coupled. To avoid inconsistencies the simulated condensation/evaporation, the Variable Order Differential Equation (VODE) solver is employed embedded within the scheme in order to solve the coupled set of differential equations account for condensation/evaporation in each bin, mass conservation, energy conservation, and supersaturation. The setup is computationally expensive, but ensures the accurate prediction of condensation/evaporation including both the curvature effect and solute effect (i.e., Köhler Theory is explicitly included).

In determining the practical applications of the 2-D continuous spectral aerosol-droplet microphysics scheme, it is important to consider two key questions: (1) is collisioncoalescence a significant process for modulating $N_{\mathrm{d}}$ ? and (2) is regeneration important? The former is often answered by considering the ambient $\mathrm{CCN}$ number concentration and cloud depth (a measure of the adiabatic LWC). Thus, for relatively low CCN number concentrations in moist environments, collision-coalescence is an efficient mechanism for drizzle formation and it was shown that the bulk model performs worst in comparison to the 2-D bin model. The 1-D model is better able to capture the collection process, but, the model is negatively biased in terms of the predicted LWP, without regeneration, while positively biased when regeneration is accounted for. We show that regardless of the activation assumption, the 1-D bin model underpredicts $N_{\mathrm{d}}$ since, without regeneration, droplet evaporation results in a loss of aerosol and, with regeneration, the aerosols are preferentially relocated to the smaller bins that are less likely to activate on subsequent time steps. On the other hand, for relatively high CCN number concentrations, (i.e., where collision-coalescence is less efficient), the bulk model performs rather well in comparison to the explicit 2-D bin model. The 1-D model with regeneration is not able to represent the increase in LWP with increased aerosol loading that is suggested by the 2-D bin model. Again, the 1-D 
model underpredicts $N_{\mathrm{d}}$ and the coinciding dynamical feedback at cloud top causes a decrease in cloud top height and a decrease in LWP. To answer the second question, one can speculate that within a thicker stratiform cloud (i.e., the volume to surface area ratio of the cloud as a whole is larger), the relative importance of regeneration decreases since it is less likely that a parcel of air will interact with drier, entrained air. Conversely, in a thinner stratiform cloud, regeneration will likely be even more important than shown for the illustrated scenario. However, in the cases of cumulus and deep convective clouds, the turbulent nature of these clouds presents an environment conducive to entertainment and complete evaporation of droplets, even though the cloud itself is rather thick. Understanding the effects of regeneration on these clouds using the model presented here is a subject for future investigation.

It is shown that the 2-D bin model, with the explicit treatment of aerosol regeneration and scavenging, predicts an increase in LWP with increased aerosol loading while the 1$\mathrm{D}$ bin model with regeneration predicts the opposite effect, demonstrating the significance of including a physicallybased representation of regeneration (in addition to include solute effects on condensation/evaporation). The suite of simulations performed here suggests that using traditional microphysical models in the absence of aerosol regeneration on short timescales (i.e., $<3 \mathrm{~h}$ ) at night may provide results similar to the more detailed, 2-D bin method (i.e., predicted LWPs within $10 \%$ of the 2-D bin method prediction). Attempting to account for regeneration, especially when collision-coalescence is significant (and thus greatly affects the solute mass distribution), introduces a negative bias on the droplet number concentration as well as additional, erroneous feedbacks (i.e., increased entrainment at cloud top, decreased LWP, etc.).

Moreover, the simulations suggest that the droplet size distribution becomes skewed in a 1-D bin microphysics scheme toward either smaller or larger sizes in the presence and absence of an aerosol regeneration parameterization, respectively. These large shifts in the droplet size distribution can potentially have significant effects on the efficiency of the collision-coalescence process, fall speeds, and ultimately precipitation.

In situations where the efficiency of collision-coalescence and regeneration is challenging to determine a priori, the 2D continuous spectral aerosol-cloud microphysics model, in conjunction with an explicit 1-D bin microphysics model, can serve as a useful tool in determining the significant of regeneration on the chosen case and model setup.

The model, in its current state, lacks the ability to simulate mixed-phase microphysics and thus cannot be combine to studies related to, for example, mixed-phase stratiform clouds in the Arctic or deep convection. Including mixed-phase microphysics within a 2-D spectral microphysics model is computationally too expensive at present. However, one can speculate that in deep convective clouds where entrainment and detrainment of air into and out of the convective core is prevalent, regeneration could potentially play a significant role in subsequent microphysical processes (both regeneration from evaporated cloud drops and sublimated ice crystals, snow, and/or graupel). Increased instability and turbulent motions within these systems creates an environment conducive to efficient collision-coalescence, and consequently large shifts in the aerosol mass distribution. More work is needed in this regard to determine the precise importance of regeneration in mixed-phase clouds.

Acknowledgements. This work was supported by the Office of Naval Research grant N00014-10-1-0200. Computations were carried out on the CITerra Dell Cluster of the Geological and Planetary Sciences Division at Caltech.

Edited by: A. Nenes

\section{References}

Ackerman, A. S., Toon, O. B., Stevens, D. E., and Coackley Jr., J. A.: Enhancement of cloud cover and suppression of nocturnal drizzle in stratocumulus polluted by haze, Geophys. Res. Lett., 30, 7, doi:10.1029/2002GL016634, 2003.

Ackerman, A. S., Kirkpatrick, M. P., Stevens, D. E., and Toon, O. B.: The impact of humidity above stratiform clouds on indirect aerosol climate forcing, Nature, 432, 1014-1017, 2004.

Ackerman, A. S., vanZanten, M. C., Stevens, B., Savic-Jovic, V., Bretherton, C. S., Chlond, A., Golaz, J.-C., Jiang, H., Khairoutdinov, M., Krueger, S. K., Lewellen, D. C., Lock, A., Moeng, C.-H., Nakamura, K., Petters, M. D., Snider, J. R., Weinbrecht, S., and Zulauf, M.: Large-eddy simulations of a drizzling, stratocumulus-topped marine boundary layer, Mon. Weather Rev., 137, 1083-1110, doi:10.1175/2008MWR2582.1, 2009.

Albrecht, B.: Aerosols, cloud microphysics, and fractional cloudiness, Science, 245, 1227-1230, doi:10.1126/science.245.4923.1227, 1989.

Beard, K. V.: Terminal velocity and shape of cloud and precipitation drops aloft, J. Atmos. Sci., 33, 851-864, 1976.

Beheng, K. D.: A parameterization of warm cloud microphysical conversion processes, Atmos. Res., 33, 193-206, 1994.

Bott, A.: A flux method for the numerical solution of the stochastic collection equation, J. Atmos. Sci., 55, 2284-2293, 1998.

Bott, A.: A flux method for the numerical solution of the stochastic collection equation: Extension to two-dimensional particle distributions, J. Atmos. Sci., 57, 284-294, 2000.

Bretherton, C. S., Blossey, P. N., and Uchida, J.: Cloud droplet sedimentation, entrainment efficiency, and subtropical stratocumulus albedo, Geophys. Res. Lett., 34, L03813, doi:10.1029/2006GL027648, 2007.

Brown, P. N., Bryne, G. D., and Hindmarsh, A. C.: VODE: A variable coefficient ODE solver, J. Sci. Stat. Comput., 10, 1038$1051,1989$.

Chen, Y.-C., Xue, L., Lebo, Z. J., Wang, H., Rasmussen, R. M., and Seinfeld, J. H.: A comprehensive numerical study of aerosolcloud-precipitation interactions in marine stratocumulus, Atmos. 
Chem. Phys., 11, 9749-9769, doi:10.5194/acp-11-9749-2011, 2011.

Chuang, P. Y., Charlson, R. J., and Seinfeld, J. H.: Kinetic limitations on droplet formation in clouds, Nature, 390, 94-96, 1997.

Del Genio, A. D., Yao, M.-S., Kovari, W., and Lo, K. K.-W.: A prognostic cloud water parameterization for global climate models, J. Climate, 9, 270-304, 1996.

Duynkerke, P. G., de Roode, S. R., van Zanten, M. C., Calvo, J., Cuxart, J., Cheinet, S., Chlond, A., Grenier, H., Jonker, P. J., Kohler, M., Lenderink, G., Lewellen, D., Lappen, C.-L., Lock, A. P., Moeng, C.-H., Muller, F., Olmeda, D., Piriou, J.-M., Sanchez, E., and Sednev, I.: Observations and numerical simulations of the diurnal cycle of the EUROCS stratocumulus case, Q. J. Roy. Meteorol. Soc., 604, 3269-3296, 2004.

Fan, J., Yuan, T., Comstock, J. M., Ghan, S., Khain, A., Leung, L. R., Li, Z., Martins, V. J., and Ovchinnikov, M.: Dominant role by vertical wind shear in regulating aerosol effects on deep convective clouds, J. Geophys. Res., 114, D22206, doi:10.1029/2009JD012352, 2009.

Feingold, G., Tzivion, S., and Levin, Z.: Evolution of raindrop spectra. Part I: solution to the stochastic collection/breakup equation using the method of moments, J. Atmos. Sci., 45, 3387-3399, 1988.

Feingold, G., Walko, R. L., Stevens, B., and Cotton, W. R.: Simulations of marine stratocumulus using a new microphysical parameterization scheme, Atmos. Res., 47, 505-528, 1998.

Ferek, R. J., Garret, T., Hobbs, P. V., Strader, S., Johnson, D., Taylor, J. P., Nielsen, K., Ackerman, A. S., Kogan, Y., Liu, Q., Albrecht, B. A., and Babb, D.: Drizzle suppression in ship tracks, J. Atmos. Sci., 57, 2707-2728, 2000.

Ferrier, B. S.: A double-moment multiple-phase four-class bulk ice scheme. Part I: Description, J. Atmos. Sci., 51, 249-280, 1994.

Geresdi, I.: Idealized simulation of the Colorado hailstorm case: Comparison of bulk and detailed microphysics, Atmos. Res., 45, 237-252, 1998.

Geresdi, I. and Rasmussen, R. M.: Freezing drizzle formation in stably stratified layer clouds. Part II: The role of giant nuclei and aerosol particle size distribution and solubility, J. Atmos. Sci., 62, 2037-2057, 2005.

Harrington, J. Y., Feingold, G., and Cotton, W. R.: Radiative impacts on the growth of a population of drops within simulated summertime Arctic stratus, J. Atmos. Sci., 57, 766-785, 2000.

Hill, A. A., Dobbie, S., and Yin, Y.: The impact of aerosols on non-precipitating marine stratocumulus. Model description and prediction of the indirect effect, Q. J. Roy. Meteorol. Soc., 134, 1143-1154, doi:10.1002/qj.278, 2008.

Hill, A. A., Feingold, G., and Jiang, H.: The influence of entrainment and mixing assumption on aerosol-cloud interactions in marine stratocumulus, J. Atmos. Sci., 66, 1450-1464, 2009.

Hong, S.-Y. and Lim, J.-O. J.: The WRF single-moment 6-class microphysics scheme (WSM6), J. Korean Meteor. Soc., 42, 129$151,2006$.

Hong, S.-Y., Dudhia, J., and Chen, S.-H.: A revised approach to ice microphysical processes for the bulk parameterization of clouds and precipitation, Mon. Weather Rev., 132, 103-1120, 2004.

Khain, A. and Lynn, B.: Simulation of a supercell storm in clean and dirty atmosphere using weather research and forecasting model with spectral bin microphysics, J. Geophys. Res., 114, D19209, doi:10.1029/2009JD011827, 2009.
Khain, A. and Pokrovsky, A.: Simulation of effects of atmospheric aerosols on deep turbulent convective clouds using a spectral microphysics mixed-phase cumulus cloud model. Part II: Sensitivity study, J. Atmos. Sci., 61, 2983-3001, 2004.

Khain, A., Ovtchinnikov, M., Pinsky, M., Pokrovsky, A., and Krugliak, H.: Notes on the state-of-the-art numerical modeling of cloud microphysics, Atmos. Res., 55, 159-224, 2000.

Khain, A., Pokrovsky, A., Pinsky, M., Seifert, A., and Phillips, V.: Simulation of effects of atmospheric aerosols on deep turbulent convective clouds using a spectral microphysics mixed-phase cumulus cloud model. Part I: Model description and possible applications, J. Atmos. Sci., 161, 2963-2982, 2004.

Khairoutdinov, M. and Kogan, Y.: A new cloud physics parameterization in a Large-Eddy Simulation model of marine stratocumulus, Mon. Weather Rev., 128, 229-243, 2000.

Kogan, Y. L.: The simulation of a convective cloud in a 3D model with explicit microphysics. Part I: Model description and sensitivity experiments, J. Atmos. Sci., 48, 1160-1189, 1991.

Kogan, Y. L., Khairoutdinov, M. P., Lilly, D. K., Kogan, Z. N., and Liu, Q.: Modeling of stratocumulus cloud layers in a large-eddy simulation model with explicit microphysics, J. Atmos. Sci., 52, 2923-2940, 1995.

Korolev, A. and Isaac, G.: Phase transformation of mixedphase clouds, Q. J. Roy. Meteorol. Soc., 129, 19-38, doi:10.1256/qj.01.203, 2003.

Lebo, Z. J. and Seinfeld, J. H.: Theoretical basis for convective invigoration due to increased aerosol concentration, Atmos. Chem. Phys., 11, 5407-5429, doi:10.5194/acp-11-5407-2011, 2011.

Li, G., Wang, Y., and Zhang, R.: Implementation of a twomoment bulk microphysics scheme to the WRF model to investigate aerosol-cloud interaction, J. Geophys. Res., 113, D15211, doi:10.1029/2007JD009361, 2008.

Lim, K.-S. S. and Hong, S.-Y.: Development of an effective doublemoment cloud microphysics scheme with prognostic cloud condensation nuclei $(\mathrm{CCN})$ for weather and climate models, Mon. Weather Rev., 138, 1587-1612, 2010.

Lin, Y.-L., Farley, R. D., and Orville, H. D.: Bulk parameterization of the snow field in a cloud model, J. Clim. Appl. Meteor., 22, 1065-1092, 1983.

Lu, M.-L. and Seinfeld, J. H.: Study of the aerosol indirect effect by large-eddy simulation of marine stratocumulus, J. Atmos. Sci., 62, 3909-3932, 2005.

Lu, M.-L. and Seinfeld, J. H.: Effect of aerosol number concentration on cloud droplet dispersion: A large-eddy simulation study and implications for aerosol indirect forcing, J. Geophys. Res., 111, D02207, doi:10.1029/2005JD006419, 2006.

Mitra, S. K., Brinkmann, J., and Pruppacher, H. T.: A wind tunnel study on the drop-to-particle conversion, J. Aerosol Sci., 23, 245-256, 1992.

Morrison, H. and Gettelman, A.: A new two-moment bulk stratiform cloud microphysics scheme in the community atmosphere model, version 3 (CAM3). Part I: Description and numerical tests, J. Climate, 21, 3642-3659, 2008.

Morrison, H. and Pinto, J. O.: Mesoscale modeling of springtime Arctic mixed-phase stratiform clouds using a new two-moment bulk microphysics scheme, J. Atmos. Sci., 62, 3683-3704, 2005.

Morrison, H., Curry, J. A., and Khvorostyanov, V. I.: A new doublemoment microphysics parameterization for application in cloud and climate models. Part I: Description, J. Atmos. Sci., 62, 1665- 
1677, 2005.

Ovchinnikov, M. and Easter, R. C.: Modeling aerosol growth by aqueous chemistry in a nonprecipitating stratiform cloud, J. Geophys. Res., 115, D14210, doi:10.1029/2009JD012816, 2010.

Pruppacher, H. R. and Klett, J. D.: Microphysics of Clouds and Precipitation, Kluwer Academic Publishers, Boston, 1997.

Radke, L. F., Coakley Jr., J. A., and King, M. D.: Direct and remote sensing observations of the effects of ships on clouds, Science, 245, 1146-1149, 1989.

Rasch, P. J. and Kristjansson, J. E.: A comparison of the CCM3 model climate using diagnosed and predicted condensate parameterizations, J. Climate, 11, 1587-1614, 1998.

Rasmussen, R. M., Geresdi, I., Thompson, G., Manning, K., and Karplus, E.: Freezing drizzle formation in stably stratified layer clouds: The role of radiative cooling of cloud droplets, cloud condensation nuclei, and ice initiation, J. Atmos. Sci., 59, 837860, 1987.

Reisin, T., Levin, Z., and Tzivion, S.: Rain production in convective clouds as simulated in an axisymmetric model with detailed microphysics. Part I: Description of the model, J. Atmos. Sci., 53, 497-519, 1996.

Roeckner, E., Bäuml, G., Bonaventura, L., Brokopf, R., Esch, M., Giorgetta, M., Hagermann, S., Kirchner, I., Kornblueh, L., Manzini, E., Rhodin, A., Schlese, U., Schulzweida, U., and Thompins, A.: The atmospheric general circulation model ECHAM5, Part I: Model description, Max-Planck-Institute for Meteorology, 2003.

Rogers, R. R. and Yau, M. K.: A Short Course in Cloud Physics, Butterworth-Heinemann, 1989.

Rotstayn, L. D.: A physically based scheme for the treatment of stratiform clouds and precipitation in large-scale models. I: Description and evaluation of the microphysical processes, Q. J. Roy. Meteorol. Soc., 123, 1227-1282, 1997.

Rotstayn, L. D. and Liu, Y.: Sensitivity of the first indirect aerosol effect to an increase of cloud droplet spectral dispersion with droplet number concentration, J. Climate, 26, 3476-3481, 2003a.

Rotstayn, L. D. and Liu, Y.: Cloud droplet spectral dispersion and the indirect aerosol effect: Comparison of two treatments in a GCM, Geophys. Res. Lett., 36, L10801, doi:10.1029/2009GL038216, 2003b.

Rutledge, S. A. and Hobbs, P. V.: The mesoscale and microscale structure and organization of clouds and precipitation in midlatitude cyclones. VIII: A model for the "seeder-feeder" process in warm-frontal rainbands, J. Atmos. Sci., 40, 1185-1206, 1983.

Rutledge, S. A. and Hobbs, P. V.: The mesoscale and microscale structure and organization of clouds and precipitation in midlatitude cyclones. XII: A diagnostic modeling study of precipitation development in narrow cold-frontal rainbands, J. Atmos. Sci., 41, 2949-2972, 1984.

Sandu, I., Brenguier, J.-L., Geoffroy, O., Thouron, O., and Masson, V.: Aerosol impacts on the diurnal cycle of marine stratocumulus, J. Atmos. Sci., 65, 2705-2718, 2008.

Sandu, I., Brenguier, J.-L., Thouron, O., and Stevens, B.: How important is the vertical structure for the representation of aerosol impacts on the diurnal cycle of marine stratocumulus?, Atmos. Chem. Phys., 9, 4039-4052, doi:10.5194/acp-9-4039-2009, 2009.

Shao, H. and Liu, G.: A critical examination of the observed first aerosol indirect effect, J. Atmos. Sci., 66, 1018-1032, 2009.
Simpson, W.-K. T. J., Baker, D., Braun, S., Chou, M.-D., Ferrier B., Johnson, D., Khain, A., Lang, S., Lynn, B., Shie, C.-L., Starr, D., Sui, C.-H., Wang, Y., and Wetzel, P.: Microphysics, radiation and surface processes in the Goddard Cumulus Ensemble (GCE) model, Meteor. Atmos. Phys., 82, 97-137, 2003.

Skamarock, W. C., Klemp, J. B., Dudhia, J., Gill, D. O., Barker, D. M., Duda, M. G., Huang, X.-Y., Wang, W., and Powers, J. G.: A description of the advanced research WRF Version 3, National Center for Atmospheric Research, Boulder, Colorado, USA, 2008.

Stevens, B., Feingold, G., Cotton, W. R., and Walko, R. L.: Elements of the microphysical structure of numerically simulated nonprecipitating stratocumulus, J. Atmos. Sci., 53, 980-1006, 1996.

Stevens, B., Cotton, W. R., Feingold, G., and Moeng, C.H.: Large-eddy simulations of strongly precipitating, shallow, stratocumulus-topped boundary layers, J. Atmos. Sci., 55, 36163638, 1998.

Stevens, B., Lenscho, D. H., Faloona, I., Moeng, C.-H., Lilly, D. K., Blomquist, B., Valie, G., Bandy, A., Campos, T., Gerber, H., Haimov, S., Morley, B., and Thornton, D.: On entrainment rates in nocturnal marine stratocumulus, Q. J. Roy. Meteorol. Soc., 129, 3469-3493, doi:10.1256/qj.02.202, 2003.

Stevens, B., Moeng, C.-H., Ackerman, A. S., Bretherton, C. S., Chlond, A., De Roode, S., Edwards, J., Golaz, J., Jiang, H., Khairoutdinov, M., Kirkpatrick, M. P., Lewellen, D. C., Lock, A., Muller, F., Stevens, D. E., Whelan, E., and Zhu, P.: Evaluation of large-eddy simulations via observations of nocturnal marine stratocumulus, Mon. Weather Rev., 133, 1443-1462, 2005.

Sundqvist, H.: Parameterization of condensation and associated clouds in models for weather prediction and general circulation simulation, in: Physically-based modelling and simulation of climate and climate change, Part 1, edited by Schlesinger, M. E., pp. 433-462, Kluwer Academic Publishers, 1988.

Thompson, G., Field, P. R., and Rasmussen, R. M.: Explicit forecasts of winter precipitation using and improved bulk microphysics scheme. Part I: Description and sensitivity analysis, Mon. Weather Rev., 132, 519-542, 2004.

Thompson, G., Field, P. R., Rasmussen, R. M., and Hall, W. D.: Explicit forecasts of winter precipitation using and improved bulk microphysics scheme. Part II: Implementation of a new snow parameterization, Mon. Weather Rev., 136, 5095-5115, 2008.

Tzivion, S., Feingold, G., and Levin, Z.: An efficient numerical solution to the stochastic collection equation, J. Atmos. Sci., 44, 3139-3149, 1987.

Tzivion, S., Feingold, G., and Levin, Z.: The Evolution of raindrop spectra. Part II: Collisional collection/breakup and evaporation in a rainshaft, J. Atmos. Sci., 46, 3312-3327, 1989.

Walko, R. L., Cotton, W. R., Harrington, J. Y., and Meyers, M. P.: New RAMS cloud microphysical parameterization. Part I: The single moment scheme, Atmos. Res., 38, 29-62, 1995.

Wang, H. and Feingold, G.: Modeling mesoscale cellular structures and drizzle in marine stratocumulus. Part I: Impact of drizzle on the formation and evolution of open cells, J. Atmos. Sci., 66, 3237-3256, 2009a.

Wang, H. and Feingold, G.: Modeling mesoscale cellular structures and drizzle in marine stratocumulus. Part II: The microphysics and dynamics of the boundary region between open and closed cells, J. Atmos. Sci., 66, 3257-3275, 2009b. 
Wang, H., Skamarock, W. C., and Feingold, G.: Evaluation of scalar advection schemes in the Advance Research WRF model using large-eddy simulations of aerosol-cloud-interactions, Mon. Weather Rev., 137, 2547-2558, 2009.

Wang, H., Feingold, G., Wood, R., and Kazil, J.: Modelling microphysical and meteorological controls on precipitation and cloud cellular structures in Southeast Pacific stratocumulus, Atmos. Chem. Phys., 10, 6347-6362, doi:10.5194/acp-10-6347-2010, 2010.

Wang, H., Rasch, P. J., and Feingold, G.: Manipulating marine stratocumulus cloud amount and albedo: a process-modelling study of aerosol-cloud-precipitation interactions in response to injection of cloud condensation nuclei, Atmos. Chem. Phys., 11, 4237-4249, doi:10.5194/acp-11-4237-2011, 2011.

Wang, S., Wang, Q., and Feinfold, G.: Turbulence, condensation, and liquid water transport in numerically simulated nonprecipitating stratocumulus clouds, J. Atmos. Sci., 60, 262-278, 2003.

Wood, R.: Cancellation of aerosol indirect effects in marine stratocumulus through cloud thinning, J. Atmos. Sci., 64, 26572669, doi:10.1175/JAS3942.1, 2007.
Wood, R., Kubar, T. L., and Hartmann, D. L.: Understanding the importance of microphysics and macrophysics for warm rain in marine low clouds. Part II: Heuristic models of rain formation, J. Atmos. Sci., 66, 2973-2990, 2009.

Xue, H. and Feingold, G.: Large-eddy simulations of trade wind cumulus: Investigation of aerosol indirect effects, J. Atmos. Sci., 63, 1605-1622, 2006.

Xue, L., Teller, A., Rasmussen, R., Geresdi, I., and Pan, Z.: Effects of aerosol solubility and regeneration on warm-phase orographic clouds and precipitation simulated by a detailed bin microphysics scheme, J. Atmos. Sci., 67, 3336-3354, 2010.

Yin, Y., Carslaw, K. S., and Feingold, G.: Vertical transport and processing of aerosol in a mixed-phase convective cloud and the feedback on cloud development, Q. J. Roy. Meteorol. Soc., 131, 221-245, 2005.

Zhang, M., Lin, W., Bretherton, C. S., Hack, J. J., and Rasch, P. J.: A modified formulation of fractional stratiform condensation rate in the NCAR community atmosphere model (CAM2), J. Geophys. Res., 108, D1, doi:10.1029/2002JD002523, 2003. 